\title{
Changes in Cell Size and Shape During 50,000 Generations of Experimental Evolution with Escherichia coli
}

\author{
Nkrumah A. Grant ${ }^{1,2,3^{*}}$, Ali Abdel Magid ${ }^{2}$, Joshua Franklin ${ }^{1,2}$, Yann \\ Dufour $^{1,2}$, and Richard E. Lenski ${ }^{1,2,3}$ \\ 1 Department of Microbiology and Molecular Genetics, Michigan State University, East Lansing, \\ MI 48824 \\ 2 BEACON Center for the Study of Evolution in Action, Michigan State University, East Lansing, \\ $\mathrm{MI} 48824$ \\ ${ }^{3}$ Department of Ecology, Evolutionary Biology, and Behavior Program, Michigan State \\ University, East Lansing, MI 48824
}

`Email correspondence to: Nkrumah.grant88@gmail.com 
1 Abstract. Bacteria adopt a wide variety of sizes and shapes, with many species

2 exhibiting stereotypical morphologies. How morphology changes, and over what

3 timescales, is less clear. Previous work examining cell morphology in an experiment

4 with Escherichia coli showed that populations evolved larger cells and, in some cases,

5 cells that were less rod-like. That experiment has now run for over two more decades.

6 Meanwhile, genome sequence data are available for these populations, and new

7 computational methods enable high-throughput microscopic analyses. Here, we

8 measured stationary-phase cell volumes for the ancestor and 12 populations at 2,000,

9 10,000, and 50,000 generations, including measurements during exponential growth at

10 the last timepoint. We measured the distribution of cell volumes for each sample using a

11 Coulter counter and microscopy, the latter of which also provided data on cell shape.

12 Our data confirm the trend toward larger cells, while also revealing substantial variation

13 in size and shape across replicate populations. Most populations first evolved wider

14 cells, but later reverted to the ancestral length-to-width ratio. All but one population

15 evolved mutations in rod-shape maintenance genes. We also observed many ghost-like

16 cells in the only population that evolved the novel ability to grow on citrate, supporting

17 the hypothesis that this lineage struggles with maintaining balanced growth. Lastly, we

18 show that cell size and fitness remain correlated across 50,000 generations. Our results

19 suggest larger cells are beneficial in the experimental environment, while the reversion

20 toward ancestral length-to-width ratios suggests partial compensation for the less

21 favorable surface area-to-volume ratios of the evolved cells. 
22 Importance. Bacteria exhibit great morphological diversity, yet we have only a limited

23 understanding of how their cell sizes and shapes evolve, and of how these features

24 affect organismal fitness. This knowledge gap reflects, in part, the paucity of the fossil

25 record for bacteria. Here, we revive and analyze samples extending over 50,000

26 generations from 12 populations of experimentally evolving Escherichia coli to

27 investigate the relation between cell size, shape, and fitness. Using this "frozen fossil

28 record" we show that all 12 populations evolved larger cells concomitant with increased

29 fitness, with substantial heterogeneity in cell size and shape across the replicate lines.

30 Our work demonstrates that cell morphology can readily evolve and diversify, even

31 among populations living in identical environments.

\section{Introduction}

35 For well over 100 years, cell biologists have wondered why cells adopt characteristic

36 shapes (1) and sizes (2). Cell size has been of particular interest owing to its

37 importance for organismal fitness. For example, cell size influences a bacterium's

38 susceptibility to predation by protists $(3,4)$ and phagocytosis by host immune cells $(5$,

39 6). Larger cell size has also been implicated in increasing susceptibility to

40 bacteriophages $(7,8)$ and reducing susceptibility to antibiotics $(9,10,11)$. Cell size is

41 generally tightly coupled to growth and division. Most eukaryotic cells follow a four-stage

42 cycle in which they must reach a critical mass before partitioning into daughter cells

43 (12). In contrast, the bacterial cell cycle involves less discrete periods due to the 
44 overlapping nature of cell growth, DNA replication, chromosome segregation and

45 division (13). Bacterial cells are generally larger when they are growing faster (14, 15,

46 16), in order to accommodate more genetic material $(17,13)$ and ribosomes $(18)$. These

47 facts suggest that cell size per se is a direct target of selection. However, it has also

48 been suggested that cell size is a "spandrel" (19), i.e., a phenotypic character that might

49 appear to be the product of adaptive evolution but is instead merely a byproduct of

50 natural selection acting on some other trait (20).

$51 \quad$ The distribution of cell size in prokaryotes spans many orders of magnitude (21).

52 The smallest known bacteria occur in the genus Palagibacterales; they constitute $25 \%$

53 of all marine planktonic cells, and they have average volumes of only $\sim 0.01 \mathrm{fL}(1 \mathrm{fL}=1$

$\left.54 \mu \mathrm{m}^{3}\right)(22,23)$. The largest heterotrophic bacteria, in the genus Epulopiscium, live in the

55 intestines of surgeonfish; they have cytoplasmic volumes of $\sim 2 \times 10^{6} \mathrm{fL}(24,25)$. In

56 contrast to these extremes, the average cell volumes of four widely studied bacteria-

57 Bacillus subtilis, Staphylococcus aureus, Escherichia coli, and Caulobacter

58 crescentus - range between about $0.4-3.0 \mathrm{fL}(25)$.

59 Large bacterial cells face significant challenges. Unlike multicellular eukaryotes

60 that use elaborate vasculature or similar systems to transport nutrients and waste

61 between cells, along with specialized cells to acquire nutrients from and dispose of

62 wastes to the environment, bacteria rely on diffusion to grow and reproduce $(26,27$,

63 28). Diffusion must be considered from two perspectives. A cell must first acquire

64 nutrients from the environment at the cell surface, and those nutrients must then diffuse

65 internally to their sites of biochemical processing in a timely fashion. As cells grow, 
66 volume generally increases faster than surface area, such that the surface area-to-

67 volume (SA/V) ratio decreases. The SAN ratio might thus constrain viable cell sizes, as

68 cells that are too large may be unable to obtain nutrients at a sufficient rate to service

69 the demands of their biomass. However, bacteria have evolved a number of strategies

70 that increase their rates of nutrient acquisition for a given cell volume. Rod-shaped cells,

71 for example, experience a smaller reduction in their SA/V ratio as they grow larger than

72 do spherical cells. Other examples include various extracellular projections that allow

73 surface attachment while generating biomechanical motion to refresh the medium in the

74 cell's immediate environment (29); chemotaxis, which allows cells to move along

75 gradients of increasing nutrient concentration (30); and invaginated cell envelopes,

76 which increase the SAN ratio (31).

The surface area of a spherocylindrical (i.e., rod-shaped) cell is given by $S \approx$

$782 \gamma V^{\frac{2}{3}}$, where $\gamma=\eta \pi\left(\frac{\eta \pi}{4}-\frac{\pi}{12}\right)^{-\frac{2}{3}}$ and $\eta$ is the aspect ratio, i.e., the cell's length divided

79 by its width (32). For rod-shaped species like $E$. coli, the SAN ratio can be varied by

80 changing either a cell's length or width, while holding the volume constant. Assuming

81 that the rod shape is maintained, doubling a cell's width reduces its SA/V ratio by much

82 more than doubling its length (33). If all else were equal, then SA/N considerations

83 would predict relatively larger cells during nutritional upshifts (resources plentiful) and

84 smaller cells during nutritional downshifts (resources scarce).

Now, suppose a bacterial population resides in a simple environment, one free of

86 predators and stressors and with a predictable supply of carbon. As this population

87 adapts to this environment by natural selection, the cells grow slightly faster. Do the 
88 cells also become larger, and if so, how much larger? Does cell size constrain the

89 maximum growth rate that can be achieved, or is the causality in the opposite direction?

90 If the cells evolve to become larger, are they larger while growing, in stationary phase

91 when the limiting resource is depleted, or both? And what might change about the

92 shapes of the cells including their aspect and SA/V ratios?

93 Experimental evolution has proven to be powerful for addressing such questions.

94 This research framework provides the opportunity to study evolution in real time, both in

95 biological $(34,35,36)$ and digital $(37,38)$ systems. In the long-term evolution

96 experiment (LTEE), 12 replicate populations of $E$. coli were started from a common

97 ancestor and have been propagated by daily serial transfer in a minimal glucose-limited

98 medium for more than 70,000 generations (32 years). Whole-population samples, and

99 clones from each population, have been frozen every 500 generations, creating a frozen

100 "fossil record" from which genotypic and phenotypic changes can be measured $(39,40)$.

101 Evolution proceeded most rapidly early in the LTEE. By 2,000 generations, the

102 populations were, on average, 35\% more fit than their ancestor. An increase in the

103 exponential growth rate and a reduction in the duration of the lag phase prior to growth

104 were major contributors to this improvement (41). By 50,000 generations, the average

105 population was $\sim 70 \%$ more fit than the ancestor $(42,43,44)$. The trajectory for fitness

106 relative to the ancestor is well described a power-law function, which implies that fitness

107 may continue to increase indefinitely, albeit at progressively slower rates of

108 improvement (42). 
In the first 10,000 generations, cell size was found to have increased in all 12

110 LTEE populations and their trajectories were positively correlated with fitness (40). The

111 increase in cell volume was accompanied by a concomitant decrease in numerical yield,

112 although the product of cell volume and number - the total biovolume yield-increased

113 (41). In the meantime, several populations were found to have diverged in shape,

114 producing more spherical cells $(45,46)$ and fitness has continued to increase for at least

11550,000 generations more $(42,43)$.

116 In this study, we sought to determine if cell size has continued to increase over

117 time, and whether it still tracked with fitness. To that end, we measured cell size in the

118 ancestor and the evolving populations at 2,000, 10,000 and 50,000 generations. We

119 used both a Coulter particle counter and microscopy to measure cell volumes, and

120 microscopy to characterize changes in cell shape. All 12 populations evolved larger

121 cells. As previously seen in the fitness trajectories, the rate of change in cell volumes

122 was fastest early in the experiment, and the trend was monotonically increasing over

123 time. By 50,000 generations, the average cell volume in most populations was well over

124 twice that of the ancestor, both during exponential growth and in stationary phase. The

125 evolved cells tended to increase more in width than in length during the first 10,000

126 generations, but they subsequently reverted to aspect ratios similar to the ancestral

127 strain. However, there was considerable among-population variability in shape as well

128 as size through the entire period. Analyses of genome sequence data also revealed

129 mutations in cell-rod maintenance genes in almost every population. Lastly, we

130 discovered greatly elevated cell mortality in the only population that evolved the novel 
131 ability to use citrate in the growth medium as a carbon source. Overall, our data suggest

132 that cell size and shape are important targets of selection in the LTEE.

\section{Results}

136 Our analyses and results are multi-faceted. They include: a comparison between two

137 methods used to measure cell volumes; analyses of the evolutionary trends in cell size

138 of both clones and whole-population samples; a comparison of sizes during exponential

139 growth and at stationary phase; analyses of cell shape and the subsequent identification

140 of mutations in genes known to affect cell shape; the correlation between cell size and

141 relative fitness during the LTEE; and evidence for substantial cell mortality in a unique

142 population.

144 Cell volumes measured by two methods

145 We first address whether the two approaches we used to estimate cell size provide

146 comparable results. The Coulter-counter method directly estimates particle volumes,

147 based on changes in conductance between two electrodes as cells suspended in an

148 electrolyte solution are moved through a small aperture. The microscopy method

149 involves obtaining cell images and processing them using software that defines the

150 edges of objects, segments the objects into small pieces, and integrates the segments

151 to estimate cell volumes. Fig. 1 shows the highly significant correlation in the median

152 cell volumes estimated using the two approaches for the two ancestors and 36 evolved 
153 clones from the 12 populations at three generations of the LTEE. All of these samples

154 were grown in the same LTEE conditions and measured in stationary phase at the 24-h

155 mark (i.e., when they would be transferred to fresh medium under the LTEE protocol).

156 This concordance gives us confidence that we can use either approach when it is best

157 suited to a given question. The Coulter counter method is especially well suited to

158 efficient measurement of cell volumes for many cells from each of many samples. The

159 microscopy and subsequent image processing, by contrast, is necessary to obtain

160 information on changes in cell shape.

162 Temporal trends in cell size in evolved clones

163 It was previously reported that cell size increased in parallel across all 12 LTEE

164 populations through 10,000 generations, and that the increase in cell volume was

165 strongly correlated with the populations' improved fitness in the LTEE environment (40).

166 Subsequent papers reported continued fitness gains in the LTEE populations for an

167 additional 40,000 generations $(42,43)$, albeit at a declining rate of improvement. Here

168 we ask whether cell size also continued to increase, focusing first on the clones isolated

169 from each population at 2,000, 10,000 and 50,000 generations and measured during

170 stationary phase.

171 Fig. 2A shows that the evolved clones were all larger than their ancestors,

172 although cell size did not always increase monotonically over the course of the LTEE.

173 The median cell volumes of clones sampled from three populations (Ara-2, Ara-3, and

174 Ara-6) were smaller at 10,000 generations than at 2,000 generations. Nonetheless, the 
175 median cell volumes of all 12 populations at 50,000 generations were greater than at

17610,000 generations. However, the measurement noise associated with the rather small

177 number of biological replicates (i.e., independent cultures) for each clone, and the

178 requirement to correct for multiple hypothesis tests, make it difficult to statistically

179 ascertain the changes in cell volume between clones from successive generations. One

180 possibility is that individual clones are not always representative of the populations from

181 which they were sampled. If that were the case, then we would expect to see more

182 consistent temporal trends in whole-population samples than in clones. We will address

183 that issue in the next section. On balance, the median cell volumes of the evolved

184 clones were on average 1.49, 1.68, and 2.55 times greater than the ancestor at 2,000,

185 10,000, and 50,000 generations, respectively (one-tailed paired $t$-tests: $p=0.0067$,

1860.0019 , and 0.0006, respectively).

187 Besides the possible reversals in median cell size between 2,000 and 10,000

188 generations in a few populations, two other unusual cases are noteworthy. The 50,000-

189 generation clone from population Ara-3 had by far the largest cells, with a median cell

190 volume that was $\sim 1.6$ times greater than any other population at the same time point

191 (Fig. 2A). That population is the only LTEE population that evolved the capacity to use

192 the abundant citrate in the DM25 medium as an additional carbon source beyond the

193 glucose that limits the other populations $(47,48)$. The Cit ${ }^{+}$phenotype is clearly

194 advantageous, although it should also be noted that growth is slower on citrate than on

195 glucose (49). Given that slower-growing E. coli cells tend to be smaller than faster-

196 growing cells $(14,15,16,50)$, and that this population's growth shifts in an apparent 
197 diauxic manner from glucose to citrate (49), it is surprising that this clone produces the

198 largest stationary-phase cells of any clone we examined. Perhaps these cells are

199 sequestering unused carbon, accounting for their large size; or perhaps the evident

200 stress they face during growth on citrate (49) leads to some decoupling of their growth

201 and division. The other noteworthy population is Ara+1, which showed the smallest

202 increase in cell volume (Fig. 2A). This population also achieved the smallest fitness

203 gains of any of the LTEE populations $(42,43)$. Given that growth rate is the main

204 determinant of fitness in the LTEE (41), it is therefore interesting (but not surprising) that

205 Ara+1 is both the least fit and produces the smallest cells of any of the LTEE

206 populations.

207 Fig. 3A compares average cell volumes of the clones between the consecutive

208 generations sampled. These analyses show that average cell size across the 12 LTEE

209 lines increased significantly from the ancestor to generation 2,000, and between 10,000

210 and 50,000 generations; however, the increase between 2,000 and 10,000 generations

211 was not significant.

212

213 Monotonic cell size trends among whole populations

214 We have so far established that the cell volume of clones usually, but not always,

215 increased between the generations tested. However, the evolutionary changes in clones

216 are not always representative of the populations from which they are sampled. For this

217 reason, we measured the cell volumes of whole-population samples at the same three

218 generations to see whether they might show more consistent temporal trends. Fig. 2B 
219 shows the cell volume trajectories for these measurements. Indeed, the population

220 samples showed more consistent trends toward larger cells than did the clones. The

221 grand mean trend of the whole populations (Fig. 3B) closely mirrored the overall trend

222 seen for clones (Fig. 3A). However, the correlation between cell volumes measured on

223 clones and whole populations, while highly significant overall, also showed considerable

224 scatter (Fig. S1), indicating that individual clones are not always representative of the

225 populations from where they were sampled. One such difference was that the median

226 volume in the 50,000-generation whole-population sample of Ara-3 was no longer an

227 outlier when compared to the other populations (Fig. 2B), in contrast to the

228 measurements on the individual clones (Fig. 2A). Another difference was the increase in

229 median cell size from the ancestral state to generation 50,000 was much greater in the

230 whole-population sample of Ara+1 than in the individual clone.

231 Overall, the temporal trend in cell volume does not appear to have reached any

232 upper bound or asymptote, as each generation of whole-population samples that we

233 tested had significantly larger cells than the preceding generation (Fig. 3B). However,

234 the intervals between samples were also progressively longer. Therefore, we calculated

235 the average rate of change in cell volume from the slopes calculated for each population

236 between adjacent time points (Fig. 4). The average rate of cell volume increase was

$237 \sim 0.17 \mathrm{fL}$ per thousand generations in the first 2,000 generations but dropped to $\sim 0.02$

238 and $0.007 \mathrm{fL}$ per thousand generations in the following 8,000- and 40,000-generation

239 intervals, respectively. In summary, these data show that cell size has continued to 
240 increase throughout the long duration of the LTEE, albeit at a decelerating pace and

241 notwithstanding a few atypical evolved clones.

243 Differences in cell size between exponential and stationary phases

244 In the sections above, we established the following points: (i) there is good agreement

245 between cell volumes estimated using the Coulter particle counter and by microscopy;

246 (ii) the evolved cells are generally much larger than their ancestors; (iii) there is a nearly

247 monotonic trend over time toward larger cells, although at a declining rate and with a

248 few clones as outliers; and (iv) the independently evolving populations show substantial

249 variation in their average cell sizes after 50,000 generations. All of these conclusions

250 were obtained using cells in stationary phase, and it is of interest to ask whether they

251 also hold for exponentially growing cells. However, examining these issues with

252 exponentially growing cells presents additional challenges. In particular, owing to

253 evolved changes in growth rates and lag times (41), cells from different generations and

254 populations reach mid-exponential-phase growth at different times, complicating efforts

255 to obtain consistent measurements. In addition, the DM25 medium in which the cells

256 evolved is dilute: the stationary-phase population density of the ancestor is only $\sim 5 \mathrm{x}$

$25710^{7}$ cells per $\mathrm{mL}$, and it is even lower for most evolved clones owing to their larger cells.

258 Hence, cells in mid-exponential-phase growth are usually at densities less than $10^{7}$ cells

259 per $\mathrm{mL}$. For these reasons, and given the excellent correspondence between Coulter

260 counter and microscopic data, we measured the distribution of cell volumes for

261 exponentially growing cells using only the Coulter counter. 
We measured cell volumes of the ancestors and 50,000-generation clones from

263 all 12 LTEE populations $2 \mathrm{~h}$ and $24 \mathrm{~h}$ after they were transferred into fresh DM25

264 medium (Fig. 5). At 2h, even the ancestors have begun growing exponentially (41), and

265 none of the evolved strains grow so fast that they would have depleted the limiting

266 glucose by that time (42). The 24-h time point corresponds to when the cells are

267 transferred to fresh medium during the LTEE and hence leave stationary phase. This

268 paired sampling strategy allows us to ask how predictive the stationary-phase cell

269 volumes are of exponentially growing cells. In fact, we found a strong positive

270 correlation in cell volumes measured during exponential growth and stationary phase

271 (Fig. 6). The exponentially growing cells were consistently much larger than those in

272 stationary phase for the ancestors as well as all of the 50,000-generation clones (Fig.

273 5). For the evolved clones, the volumetric difference as a function of growth phase was

$274 \sim 2$-fold, on average (Fig. S2). It is well known that bacterial cells are larger during

275 exponential growth, with each fast-growing cell typically having multiple copies of the

276 chromosome and many ribosomes to support maximal protein synthesis. In the dilute

277 glucose-limited DM25 minimal medium, cells hit stationary phase abruptly, with the last

278 population doubling using up as much glucose as all the previous doublings combined.

279 The $\sim 2$-fold volumetric difference between the exponentially growing cells and those

280 measured many hours later in stationary phase implies that they typically undergo a

281 reductive division, either as they enter or during stationary phase. At the same time, the

282 range in size between the 12 independently evolved clones was also roughly 2-fold 
283 during both growth phases (Fig. 5), which indicates that the striking morphological

284 divergence extends across growth phases.

285

286 Changes in cell shape

287 Cell size has clearly increased during the LTEE. Has cell shape also changed? Cell

288 shape has sometimes been regarded as invariant for a given species. For example, $E$.

289 coli has rod-shaped cells that typically maintain an aspect ratio (length-to-width) of $\sim 4: 1$,

290 independent of cell volume $(51,31)$. We examined and analyzed micrographs to see

291 whether the larger cells that evolved in the LTEE maintained their ancestral aspect ratio.

292 Alternatively, larger volumes might have evolved by disproportionate increases in either

293 the length or width of cells. Yet another possibility is that the lineages diverged in their

294 aspect ratios not only from their common ancestor, but also from one another. Fig. 7

295 shows representative micrographs of the ancestors and the 50,000 -generation clones. It

296 is readily apparent that the different lineages have evolved different aspect ratios. To

297 investigate these differences more systematically, we processed multiple micrographs

298 of the ancestors and clones from generations 2,000, 10,000, and 50,000 using the

299 SuperSegger package (52). Across all of the samples in total, we obtained lengths and

300 widths (cross-sectional diameters) from >87,000 cells (see Methods). As a reminder, an

301 increase in the aspect ratio relative to the ancestor implies a higher SA/V ratio for a

302 given volume, whereas a decline in the aspect ratio indicates the opposite. Of course,

303 having a larger cell alone also reduces the SA/V ratio, even without a change in the

304 aspect ratio. One would typically expect a greater SAN ratio to be beneficial for 
305 resource acquisition, and therefore we might expect the evolved clones to have higher

306 aspect ratios than the ancestral strains, especially given their increased volumes.

307 In fact, however, the opposite trend held, at least for the first 10,000 generations,

308 as shown in Fig. 8. Clones from 10 of the 12 populations, at both 2,000 and 10,000

309 generations, tended to produce relatively wider than longer cells in comparison to the

310 ancestor ( $p=0.0386$ based on a two-tailed sign test at each time point). By 50,000

311 generations, the clones were split evenly: 5 had aspect ratios greater than the ancestor,

3125 had aspect ratios lower than the ancestor, and 2 had aspect ratios nearly identical to

313 the ancestor. Note that the 50,000 -generation clone from population Ara-3 is an

314 extreme outlier, with cells that are exceptionally long and very large. This population is

315 the one that evolved the novel ability to grow on citrate $(47,48,49)$, and its unusual

316 morphology is presumably related to its distinct metabolism.

317 Fig. 9A shows the average length-to-width ratios and their associated 95\%

318 confidence intervals, excluding the $\mathrm{Cit}^{+}$outlier at 50,000 generations. The ancestral

319 cells had an average length-to-width ratio of 3.37. Recall that $E$. coli has been reported

320 to typically maintain an average aspect ratio of about $4: 1(33,51,53)$. The aspect ratio

321 we see is somewhat smaller. This difference might reflect variation between strains (the

322 LTEE ancestor is a derivative of $E$. coli $\mathrm{B}$, not $\mathrm{K} 12$ ) or some other factor. In any case,

323 the mean aspect ratio across the evolved lines declined to 2.90 and 2.87 at 2,000 and

32410,000 generations, respectively, and then increased to 3.39 at generation 50,000,

325 almost identical to the ancestral ratio. The early decline in the aspect ratio is statistically

326 significant, as is the subsequent reversal (Fig. 9A). This reversal would increase the 
327 SA/V ratio somewhat. However, it might not be sufficient to offset the reduction in the

328 SA/V ratio associated with the much larger cell volumes at 50,000 generations. On

329 balance, the LTEE lines evolved larger cell volumes by first increasing

330 disproportionately in width, and later increasing their length, possibly to the benefit of a

331 somewhat more favorable SA/V ratio.

333 Analysis of changes in the SAN ratio

334 The reversion of the evolved clones to their ancestral aspect ratio (Fig. 9A), coupled

335 with their overall increase in cell volume (Fig. 3A), raises the question of how much their

336 SA/V ratios have changed. If selection to increase the diffusion of nutrients into cells is

337 strong in the LTEE, then increasing cell length would be beneficial. However, the larger

338 cell volume would have the opposite effect. To examine the net result of these changes,

339 we calculated the SAN ratio of the evolved clones using the equations for

340 spherocylindrical cells from Ojkic et al. (32), which we presented in Introduction. We

341 used the length and width values measured for clones using SuperSegger to compute

342 for each cell $\gamma$, which depends on the aspect ratio, and from that the cell's surface area.

343 We then divided that value by the cell's estimated volume to obtain its SA/V ratio. Given

344 the early trend toward wider cells (lower aspect ratios) and the larger cell volumes at

345 later generations, we expected lower SA/V ratios for the evolved clones relative to the

346 ancestors, despite the later reversion toward the ancestral aspect ratio. Indeed, all 36

347 evolved clones had a SA/V ratio that was lower than the ancestors (Fig. 10). 
Fig. 9B shows the average SA/V ratio and associated $95 \%$ confidence intervals over time. We included the 50,000-generation Ara-3 clone in this analysis because its

350 SA/V ratio (Fig. 10), unlike its aspect ratio (Fig. 8), was not an extreme outlier; that is, its

351 atypical aspect ratio was largely offset by its large average cell volume (Fig. 2A). The 352 mean SAN ratio declined monotonically and significantly from 0.461 in the ancestor to $353 \quad 0.430,0.412$, and 0.392 at 2,000, 10,000, and 50,000 generations, respectively. Even

354 the reversion to the ancestral cell aspect ratio between 10,000 and 50,000 generations

355 (Fig. 9A) was insufficient to offset the increase in cell volume over that same interval 356 (Fig. 3A).

We also performed an isometric analysis to assess the extent to which the

358 reversion to the ancestral aspect ratio between 10,000 and 50,000 generations changed

359 the SA/V ratio. To do so, we used the cell aspect ratios measured at 10,000 generations 360 and compared the average SA/V ratio at 50,000 generations to the hypothetical average 361 using the earlier aspect ratios. The average SA/V ratio at 50,000 generations was $6 \%$

362 higher as a consequence of the change in cell aspect ratio (Fig. S3), and this difference

363 was significant $(p=0.0144)$. Even so, the mean SA/V ratio continued to decline (Fig.

364 9B) because the change in average cell aspect ratio over this period (Fig. 9A) was

365 insufficient to offset the increase in average cell volume (Fig. 3A).

367 Nearly spherical cells in one LTEE population

368 While examining micrographs, we observed that cells from the Ara+5 population at 3692,000 and 10,000 generations looked like stubby rods, many of which were almost 
370 spherical (Fig. 11). By 50,000 generations, however, the cells were rod-shaped (Fig. 7),

371 suggesting that one or more mutations in morphogenic genes might contribute to this

372 phenotype.

The typical rod-shaped cell morphology in E. coli is maintained by several

374 proteins including MreB, MreC, MreD, MrdA (PBP2), and MrdB (RodA) $(46,54)$. To this

375 end, we examined published whole-genome sequence data (55) for the clones in our

376 study to identify any mutations in these genes. By 50,000 generations, all but one of the

37712 lines (Ara-5) had nonsynonymous mutations in at least one of these five shape-

378 maintaining genes (Fig. 12). There were also a few synonymous changes, which were

379 seen only in populations that had evolved point-mutation hypermutability, as well as one

380 indel. However, the majority of mutations that arose and reached high frequency in

381 these genes were nonsynonymous changes.

382 The 2000-generation clone from the Ara+5 population that produced the stubby

383 cells had a single nonsynonymous mutation in mreB. This mutation was also present in

384 the clones sampled from this population at 10,000 and 50,000 generations. There were

385 no other mutations in the other four rod-shape maintenance genes at any of the

386 timepoints. E. coli cells have been shown to become spherical when MreB is depleted

387 (54), which strongly suggests that the mreB mutation is responsible for the stubby

388 morphology observed in the early generations of this population. The fact that the Ara+5

389 cells were not stubby at 50,000 generations, despite the mreB mutation, suggests some

390 compensatory change that did not involve the five morphogenic genes considered here.

391 Four other populations also had nonsynonymous mreB mutations by generation 50,000 
392 (Fig. 12). Of these four, the clone from population Ara+1 also produced rather stubby

393 cells (Fig. 7), resulting in the lowest aspect ratio of any of the 50,000-generation clones

394 (Fig. 8). Whether the diverse effects of the mreB mutations on cell shape reflect the

395 different mutations, the genetic backgrounds on which they arose, or both remains to be 396 determined.

399 Cell size and relative fitness were previously shown to be strongly correlated during the

400 first 10,000 generations of the LTEE (40). The fitness of these populations has

401 continued to increase throughout this experiment $(42,43)$. In light of the continued

402 increase in cell volumes reported in this work, we expected that cell size and fitness

403 would continue to be correlated. To test this, we used the relative fitness data previously

404 collected for the 12 LTEE populations through 50,000 generations (42), and we asked

405 how well those fitness values correlate with the cell volumes we measured for the

406 ancestors and the whole-population samples from three later generations. Fig. 13

407 shows that cell volume and relative fitness have remained significantly correlated,

408 although with substantial scatter. Some of this scatter reflects increased measurement

409 noise when estimating relative fitness in later generations. These estimates are

410 obtained by competing the evolved populations against a marked ancestor; as the

411 relative fitness of the evolved bacteria increases, it becomes more difficult to enumerate

412 accurately the relative performance of the two competitors. 


\section{Elevated cell mortality in the population that evolved to grow on citrate}

415 We observed what we call "ghost" cells in micrographs of the 50,000-generation Cit'

416 clone from the Ara-3 population. These cells were quite distinct from the ancestral

417 strain and evolved clones from all other populations (Fig. 7). In terms of contrast with

418 their background, the ancestor and other evolved clones had uniformly dark and opaque

419 cells, in contrast to the lighter agar pad on which they were placed for imaging. Many of

420 the $\mathrm{Cit}^{+}$cells, by comparison, were translucent (Fig. 7). Most translucent cells appeared

421 intact, although we also saw some fragmented cells. We presume that the translucent

422 cells that appear intact are nonetheless either dead or dying.

423 We also grew the $\mathrm{Cit}^{+}$clone in DM0, which is the same medium as used in the

424 LTEE and our other experiments, except DM0 contains only the citrate but no glucose.

425 The proportion of ghost cells is even higher in this citrate-only medium (Fig. 14). Some

426 translucent cells had small punctations, or dots, within the cytoplasm, often at the cell

427 poles (Fig. 14). These dots are reminiscent of the polyhydroxyalkanoate storage

428 granules that some bacterial species produce under conditions where their growth is

429 unbalanced $(56,57)$ or when cells are otherwise stressed $(58,59)$. It is also possible

430 that these dots comprise the nucleoid or some other remnant of a leaky cytoplasm.

431 It is noteworthy that we observed these anomalous ghost cells at any appreciable

432 frequency only in the unique $\mathrm{Cit}^{+}$population $(47,48)$. This observation of ghost cells,

433 and the implication that many cells in this population are dead or dying, is supported by

434 other observations that indicate the $\mathrm{Cit}^{+}$cells struggle with maintaining balanced growth

435 on citrate (49). To test whether the ghost cells are dead, dying, or at least 
436 physiologically incapacitated, we labeled stationary-phase cultures using a two-color

437 live/dead stain. Our methods, full results, and in-depth analyses of these labelling

438 experiments are presented elsewhere (49). Here we present a subset of the data, with

439 an analysis that specifically compares the ancestor (REL606) and 50,000-generation

$440 \mathrm{Cit}^{+}$clone (REL11364). Fig. 15A shows representative micrographs of the ancestral and

441 evolved Cit+ cells grown to stationary phase in the standard DM25 medium that contains

442 glucose as well as citrate. Fig. 15B shows the estimated proportions of live (green) and

443 dead (red) cells, obtained by pooling data from 5 independent cultures (i.e., biological

444 replicates) for each clone. There was much more cell death in the cultures of the $\mathrm{Cit}^{+}$

445 clone when compared to the ancestor. On average, $43.6 \%$ of the $\mathrm{Cit}^{+}$cells were scored

446 as dead, based on greater intensity of the corresponding dye. By contrast, only $13.2 \%$

447 of the ancestral cells were scored as dead, and they exhibited much weaker intensity of

448 that dye (Fig. 15A). The difference in the proportion of dead cells between the ancestor

449 and the $\mathrm{Cit}^{+}$clone is highly significant $(t=2.9304, \mathrm{df}=8$, one-tailed $p=0.0094)$. This

450 result thus supports our hypothesis that the ghost cells seen in our original micrographs

451 of the $\mathrm{Cit}^{+}$clones were indeed dead or dying.

453 Discussion

455 During the first 10,000 generations of the LTEE, 12 populations of $E$. coli increased in

456 fitness and cell size as they evolved in and adapted to their glucose-limited minimal

457 medium (40). The increase in cell size was unexpected, given the fact that larger cells 
458 have greater metabolic demands and have SAN ratios that are less favorable for

459 supporting those demands. In the $>60,000$ generations since that study, the populations

460 have continued to adapt to the glucose media, and their fitness has continued to

461 increase with trajectories that are well described by a simple power law $(42,43)$. In this

462 study, we sought to determine if cell size has continued to increase, and whether cell

463 size still correlates with fitness. We measured changes in cell volume and shape for

464 clones and whole-population samples. We used two methods: a Coulter counter that

465 directly measures cell volume, and microscopy that allowed us to analyze both cell

466 volume and shape using machine learning. The average cell volumes measured using

467 the two methods were well correlated (Fig. 1).

$468 \quad$ The average cell increased monotonically over time in the whole-population

469 samples (Figs. 4-5). Clones from three populations (Ara-2, Ara-3, Ara-6) deviated

470 from this monotonic trend, producing smaller cells at 10,000 than at 2,000 generations

471 (Fig. 2A). These idiosyncratic cases implies within-population heterogeneity. They might

472 also be due, in part, to the clones being studied in an environmental context different

473 from that in which they evolved. As an indication of the relevance of both of these

474 explanations, two ecologically and genetically distinct lineages have coexisted in the

475 Ara-2 population since $\sim 6,000$ generations, with coexistence mediated by differential

476 growth on glucose and acetate, a metabolic byproduct $(60,61)$. In any case, our data

477 show that average cell size and mean fitness have remained significantly correlated in

478 the LTEE through 50,000 generations (Fig. 13), despite variation within and between

479 populations. 
We obtained most of our data on average cell size with cells in stationary phase,

481 at the end of the LTEE's standard 24-hour period prior to the transfer into fresh medium.

482 We did so because analyzing exponentially growing cells presents additional

483 challenges. In particular, the evolved cells reach exponential-phase growth faster than

484 the ancestor, owing to changes in growth rates and lag times (41). Also, cell densities

485 are lower during exponential growth, especially given the low glucose concentration in

486 the LTEE medium. Nonetheless, we performed a set of experiments to compare the

487 average volumes of exponentially growing and stationary-phase populations (Fig. 5).

488 Exponentially growing cells were larger than stationary-phase cells, and this difference

489 was observed using both the ancestor and evolved bacteria, Bacterial cells are larger

490 during exponential growth to accommodate more ribosomes (18) and replicating

491 chromosomes $(13,17)$. The approximately two-fold difference in average cell volume

492 between exponential and stationary phases for the 50,000-generation clones (Fig. S2)

493 implies that these bacteria undergo a reductive division as they enter or during

494 stationary phase.

495 The 12 LTEE populations have evolved shorter lag phases and faster maximal

496 growth rates during their adaptation to the LTEE environment. Therefore, when

497 compared to the ancestor, evolved cells spend more time in the stationary-phase period

498 between transfers. In silico models of the daily transfer regime typical of experimental

499 evolution systems, including the LTEE, have shown that virtual microbes can evolve to

500 anticipate the transfer interval (62). A reductive division during stationary phase might

501 prime the cells to grow faster when transferred into fresh medium by temporarily 
502 increasing their SA/V ratio, potentially reducing the duration of the lag phase. However,

503 we note that the LTEE ancestors also undergo a similar reductive division, as indicated

504 by smaller cells in stationary phase than during exponential growth (Fig. 5). Thus, the

505 reductive division per se does not account for the shortened lag phase in the evolved

506 bacteria. In any case, future studies might examine when this reductive division occurs

507 in the ancestral and evolved bacteria and, moreover, identify the metabolic cues and

508 physiological processes involved.

We also observed substantial heterogeneity in the cell shape of the evolved lines

510 (Fig. 7). One population (Ara+5) evolved stubby, almost spherical, cells early in the

511 LTEE (Fig. 11A), evidently caused by a mutation in mreB, which encodes a protein

512 involved in maintaining the rod shape that is typical of $E$. coli. This population later re-

513 evolved more rod-shaped cells (Fig. 11B), although the genetic basis for that change is

514 unclear. More generally, most populations evolved relatively wider cells during the first

51510,000 generations (Fig. 8), even though longer cells would have had a higher SA/V

516 ratio (33). This trend suggests that cell size evolution in the LTEE is not tightly

517 constrained by the SA/V ratio. In later generations, the average cell aspect ratio

518 (length/width) reverted to the ancestral ratio (Fig. 9A), but not enough to prevent a

519 further decline in the average SA/V ratio (Fig. 9B), as the mean cell volume continued to

520 increase (Fig. 3A).

$521 \quad$ For a given cell volume, wider cells have lower SA/V ratios than longer cells.

522 From the standpoint of acquiring limited nutrients, wider cells would therefore seem

523 maladaptive, yet that is how the LTEE populations tended to evolve for the first 10,000 
524 generations (Fig. 8). Might wider cells have had some benefit that overcame their

525 unfavorable SA/V ratios? As a bacterial cell grows in size, it simultaneously replicates

526 multiple copies of its chromosome. These copies must then be fully segregated into the

527 two daughter cells, which requires moving them away from the cell center before the

528 division can be completed (13). Rod-shaped bacteria like E. coli typically divide at the

529 middle of the cell; the midpoint is defined by the proteins MinCDE, which oscillate

530 between the cell poles every $40-90$ seconds while consuming ATP $(63,64,65,66,67$,

531 68). The number of MinCDE complexes doubles in cells longer than $\sim 4 \mu \mathrm{m}$, while their

532 oscillatory period remains constant (63). It has also been shown that MinCDE proteins

533 do not oscillate at all in shorter cells, which have a reduced aspect ratio; instead, they

534 exhibit stochastic switching between the two poles (69). This stochastic switching

535 reduces the rate at which these proteins use ATP (70). Thus, one could imagine that

536 evolving wider cells, which also have a reduced aspect ratio, would increase the ATP

537 available for other metabolic processes. Future studies might study the oscillatory

538 behavior and ATP consumption of these proteins in the LTEE lines.

539 Another potential advantage of wider cells is to minimize the macromolecular

540 crowding that occurs within the highly concentrated cellular cytoplasm (71). Gallet et al.

541 (72) suggested that the increased cell width in the LTEE lines might reduce the adverse

542 effects of macromolecular crowding, but they did not directly test this hypothesis.

543 However, they also proposed that the bacterial cells became larger in order to become

544 less densely packed, which would allow greater internal diffusion of resources and

545 macromolecules. Gallet et al. (72) found evidence in support of this second hypothesis 
546 in the one LTEE population they examined, where the cell density (dry mass-to-volume)

547 declined over evolutionary time. If the rate of resource acquisition from the external

548 environment does not limit growth, then increasing the rate of internal diffusion should

549 increase the cell's metabolic rate and, at least potentially, lead to faster growth and

550 higher fitness $(1,73,74,75,76,77,78,79)$. Therefore, it would be interesting to extend

551 the analyses performed by Gallet et al. (72) to all of the LTEE populations to assess the

552 generality of their findings.

553 We also made the serendipitous discovery that one population, called Ara-3,

554 evolved greatly elevated cell mortality (Figs. 10 and 19). That population is the only one

555 that evolved the ability to assimilate energy from citrate, which is in the LTEE medium

556 as an iron chelator (47). We subsequently showed that this increased mortality has

557 persisted in the population for almost 20,000 generations, and perhaps even longer

558 (49). The persistence of this elevated death suggests some physiological constraint that

559 is difficult to overcome, though this cost must be smaller than the benefit provided by

560 the access to this additional resource. In any case, a 50,000-generation clone that we

561 analyzed from this population was also an outlier in other morphological respects,

562 producing cells that are exceptionally large (Fig. 2A) and long (Fig. 8). In addition to the

563 many ghost-like cells that appear to be dead or dying (Fig. 7), some of these translucent

564 cells have inclusions within the cytoplasm (Fig. 14). Future studies may investigate the

565 genetic and physiological bases of these unusual morphological traits and their relation

566 to growth on citrate and cell death. 
In summary, we have observed substantial changes in cell morphology, including shape as well as size, over the course of 50,000 generations of the E. coli LTEE. Some

569 of the changes are highly repeatable including especially the parallel trend toward larger

570 cells observed in all 12 independently evolving populations. At the same time, the

571 replicate populations have evolved highly variable phenotypes, even under identical

572 conditions, leading to approximately two-fold variation in their average cell volumes (Fig.

573 5) as well as large differences in their aspect ratios (Fig. 8). The consistent trend toward

574 larger cells (Fig. 2B), the strong positive correlation of cell volume with fitness (Fig. 13),

575 and the parallel substitutions in genes involved in maintaining cell shape (Fig. 12) all

576 suggest that the evolution of cell morphology is not a mere spandrel, but instead reflects

577 adaptation to the LTEE environment. The resulting among-population variation in size

578 and shape, however, suggest that precise changes in cell morphology were not critical

579 to performance, because most populations have improved in relative fitness to a similar

580 degree (43), despite different cell morphologies. Thus, the changes in cell size and

581 shape during the LTEE reflect both natural selection and the idiosyncratic nature of the

582 chance events, including mutations, particular to every evolving lineage. 


\section{$583 \quad$ Figures and Tables}

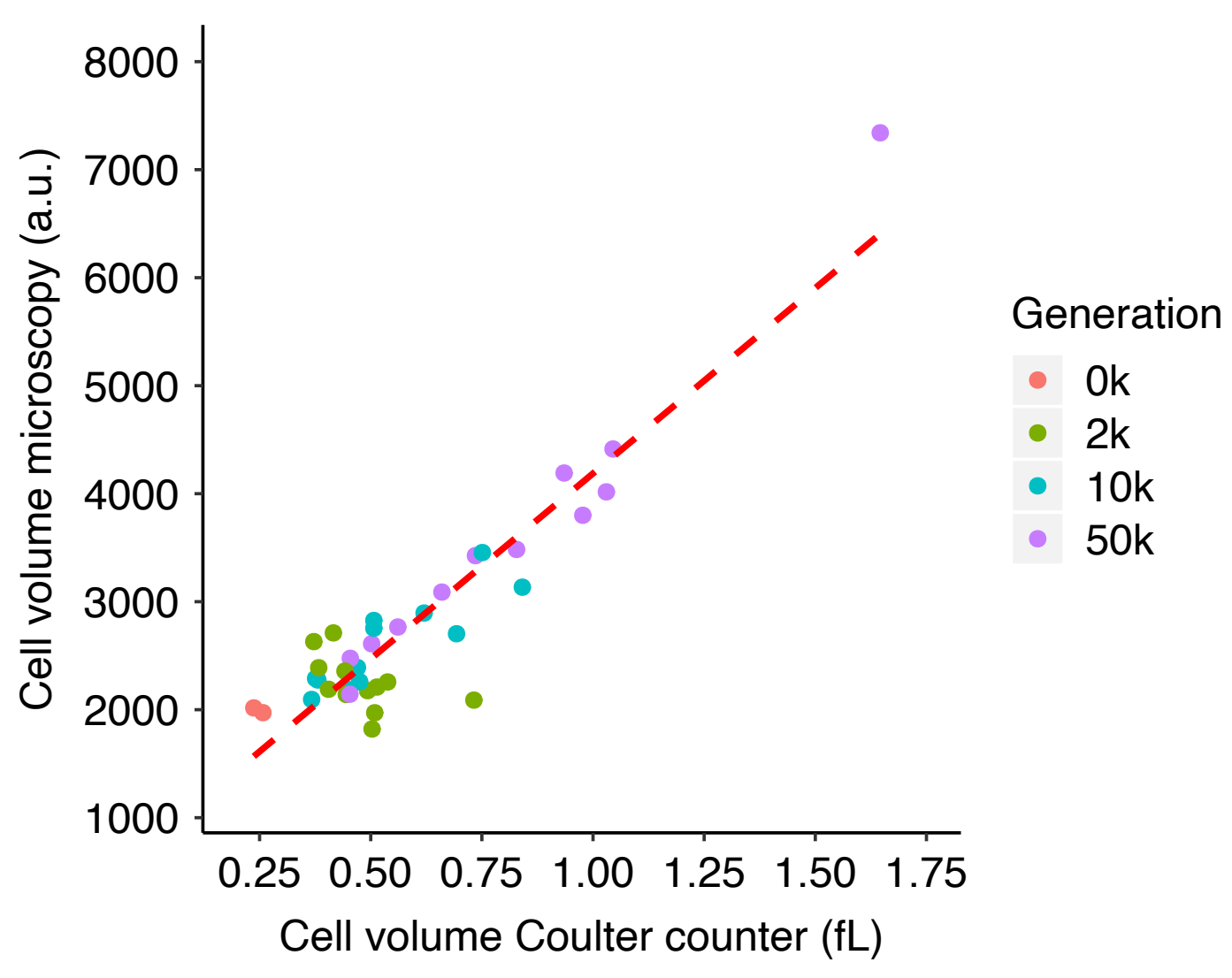

584

585

586

587 Coulter counter. Volumes obtained by microscopy are expressed in arbitrary units (a.u.)

588 proportional to $\mathrm{fL}$ (i.e., $\mu \mathrm{m}^{3}$ ); volumes obtained using the Coulter counter are expressed

589 in $\mathrm{fL}$. Each point shows the grand median of three assays for clones sampled from the 12

590 evolving populations or of 'six assays for the two ancestral strains. Kendall's coefficient $\mathrm{\tau}$

$591=0.5495, N=38, p<0.0001$. 


\section{A}

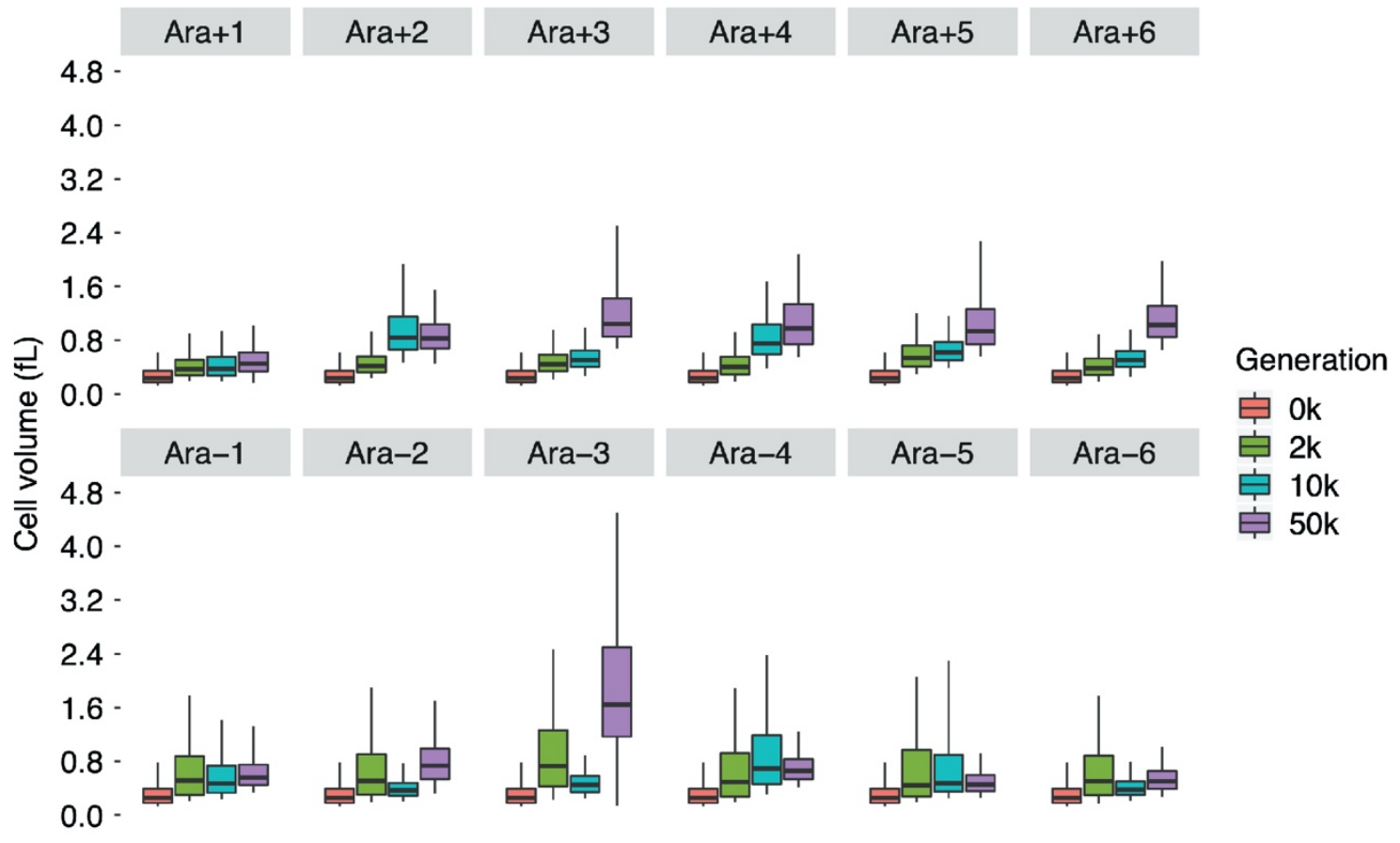

B

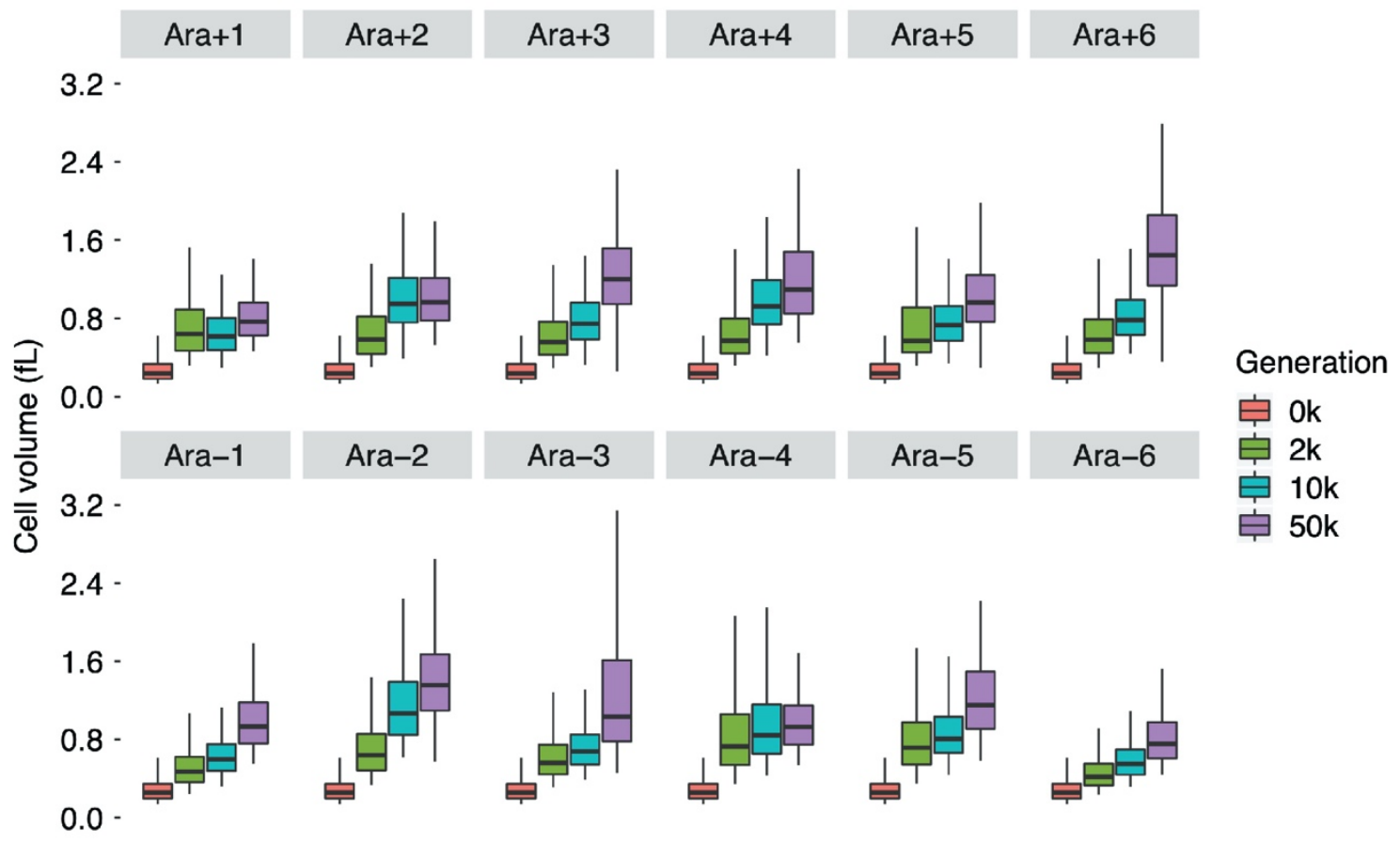

594 FIG 2. Cell size trajectories for (A) clones and (B) whole-population samples obtained

595 using Coulter counter. Each quantile (5th, 25th, 50th, 75th, and 95th) represents the 
bioRxiv preprint doi: https://doi.org/10.1101/2020 08.13.250415; this version posted August 14,2020. The copyright holder for this preprint (which was not certified by peer review) is the author/funder, who has granted bioRxiv a license to display the preprint in perpetuity. It is made available under aCC-BY-NC-ND 4.0 International license.

596 median of the corresponding quantile from six replicates of each ancestor (REL607 for

597 "Ara+" populations; REL606 for "Ara-" populations) and three replicates for cells sampled

598 from each evolving population. 
A

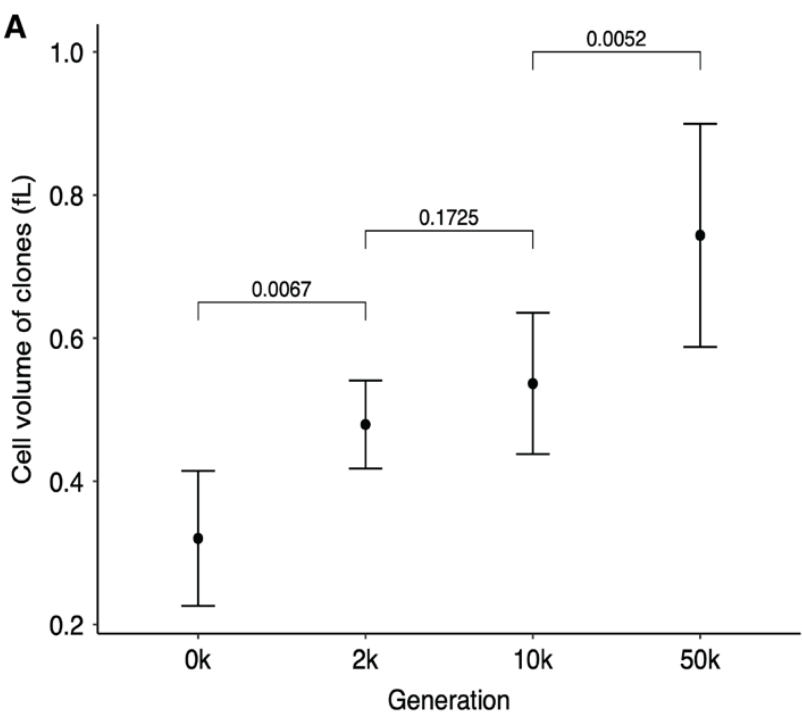

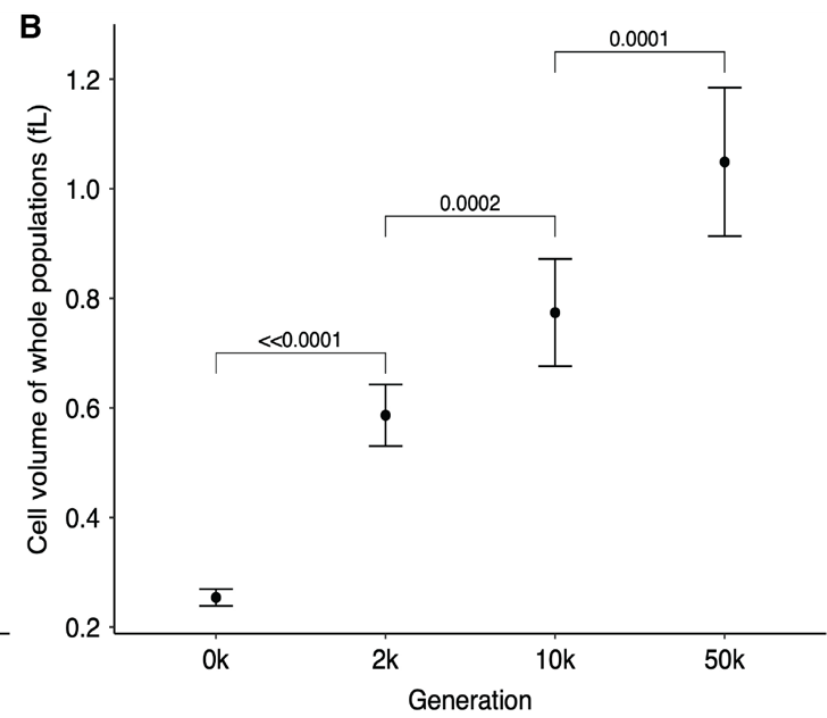

600

604 FIG 3. Tests of changes over time in average cell sizes of $(A)$ clones and (B) whole605 population samples from the 12 LTEE populations. Each point shows the grand mean of 606 the grand median cell volumes calculated for each population. The 50,000-generation 607 clone from population Ara-3 was an extreme outlier (FIG 2A) and is excluded in panel A; 608 however, the 50,000-generation whole-population sample from this population was not 609 an outlier (FIG 2B). Error bars are 95\% confidence intervals, and brackets show the 610 statistical significance ( $p$ value) based on one-tailed paired $t$-tests. The last comparison 611 in panel A remains significant even if one includes the outlier clone $(p=0.0090)$. 


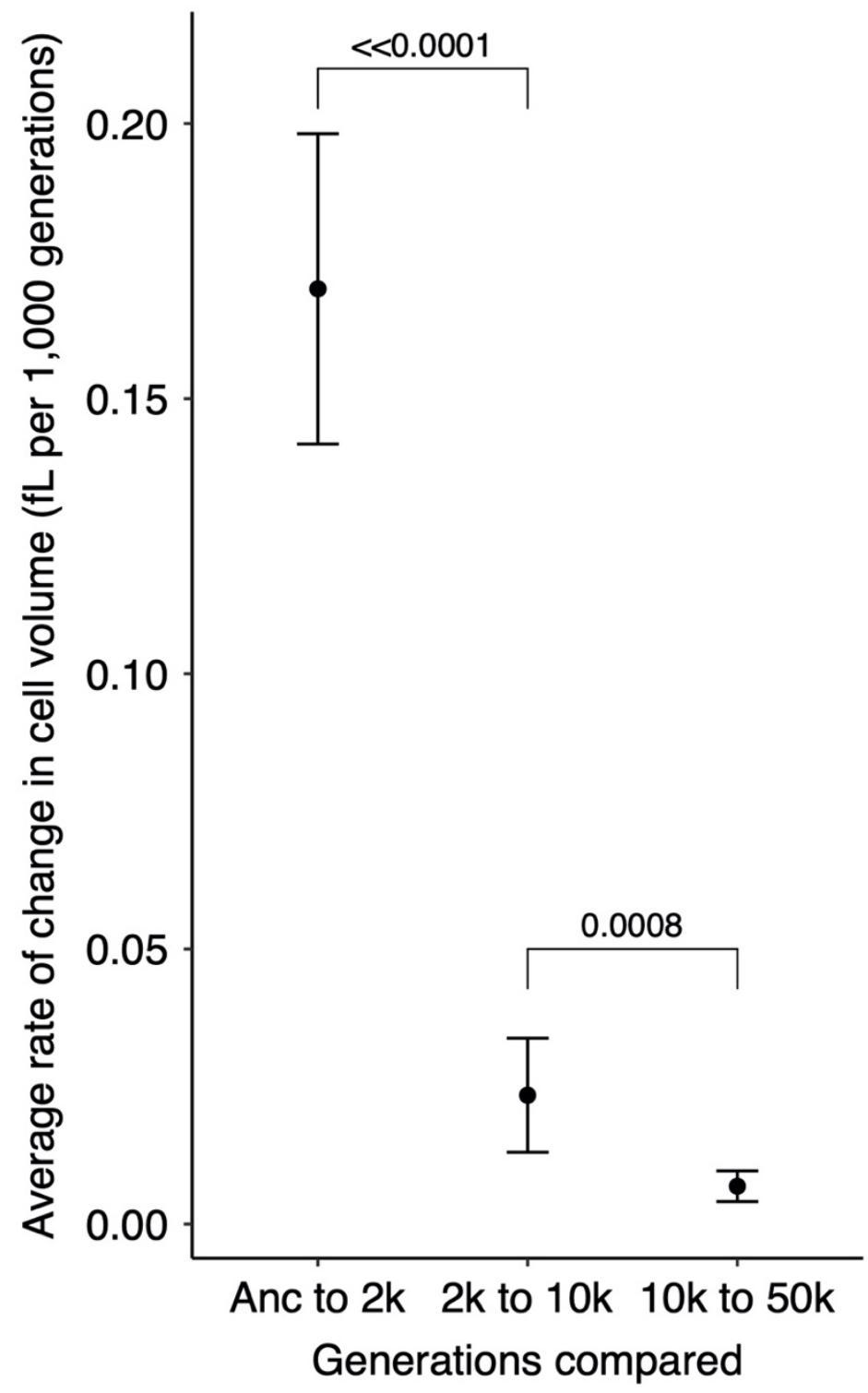

FIG 4. Average rate of cell volume increase. Slopes were calculated for each population

617 over each of three intervals. Each point shows the grand mean for the 12 populations.

618 Error bars are 95\% confidence intervals, and brackets show the statistical significance (p

619 value) based on one-tailed Wilcoxon tests, which account for the paired nature of the samples. 


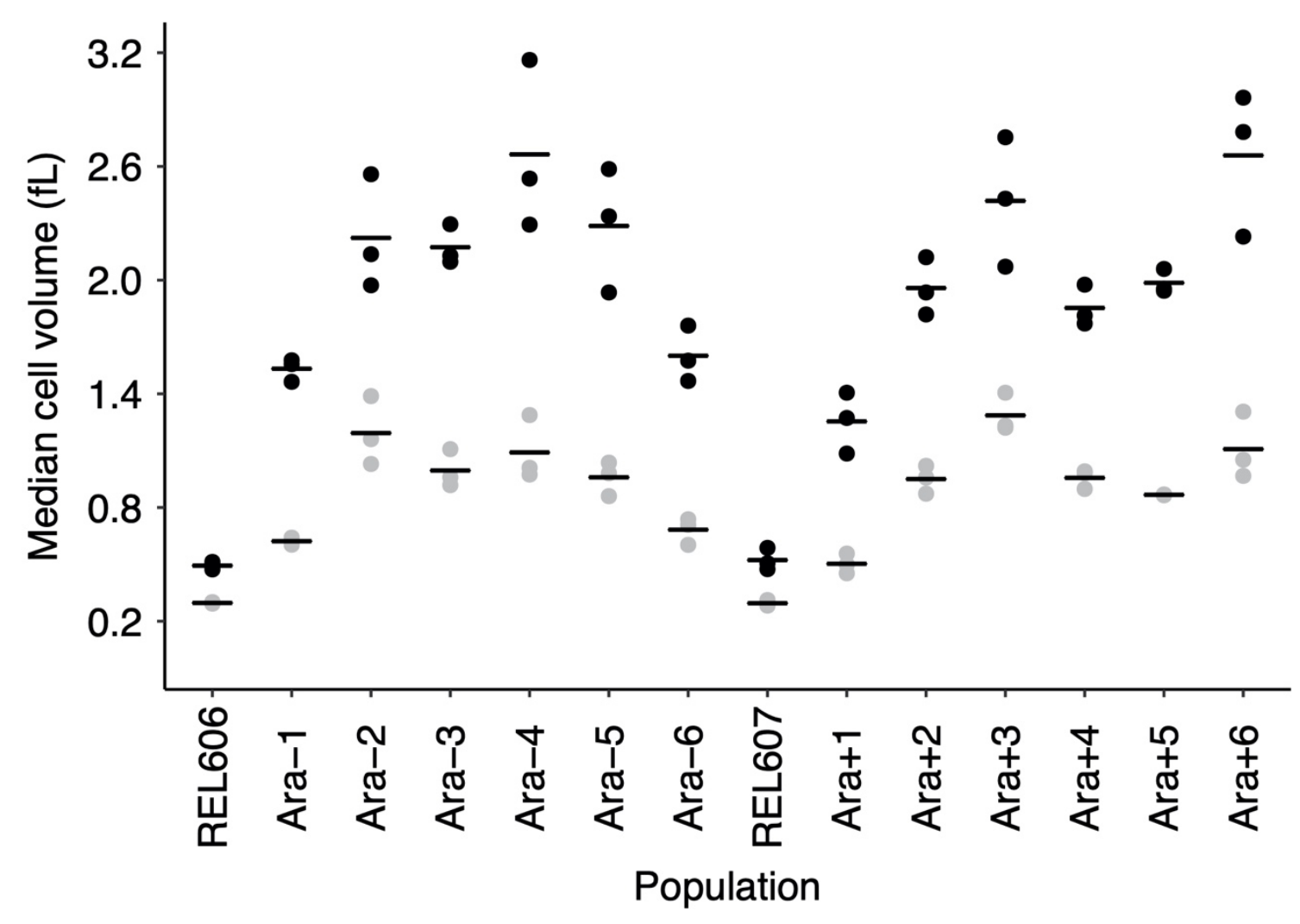

624 FIG 5. Cell sizes measured during exponential and stationary phases of ancestral strains

625 and 50,000-generation clones from all 12 populations. Each point represents the median

626 cell volume for one assay at either $2 \mathrm{~h}$ (exponential growth) or $24 \mathrm{~h}$ (stationary phase) in

627 DM25. Horizontal bars are the means of the 3 replicate assays for each strain. The points

628 for some individual replicates are not visible because some values were almost identical. 


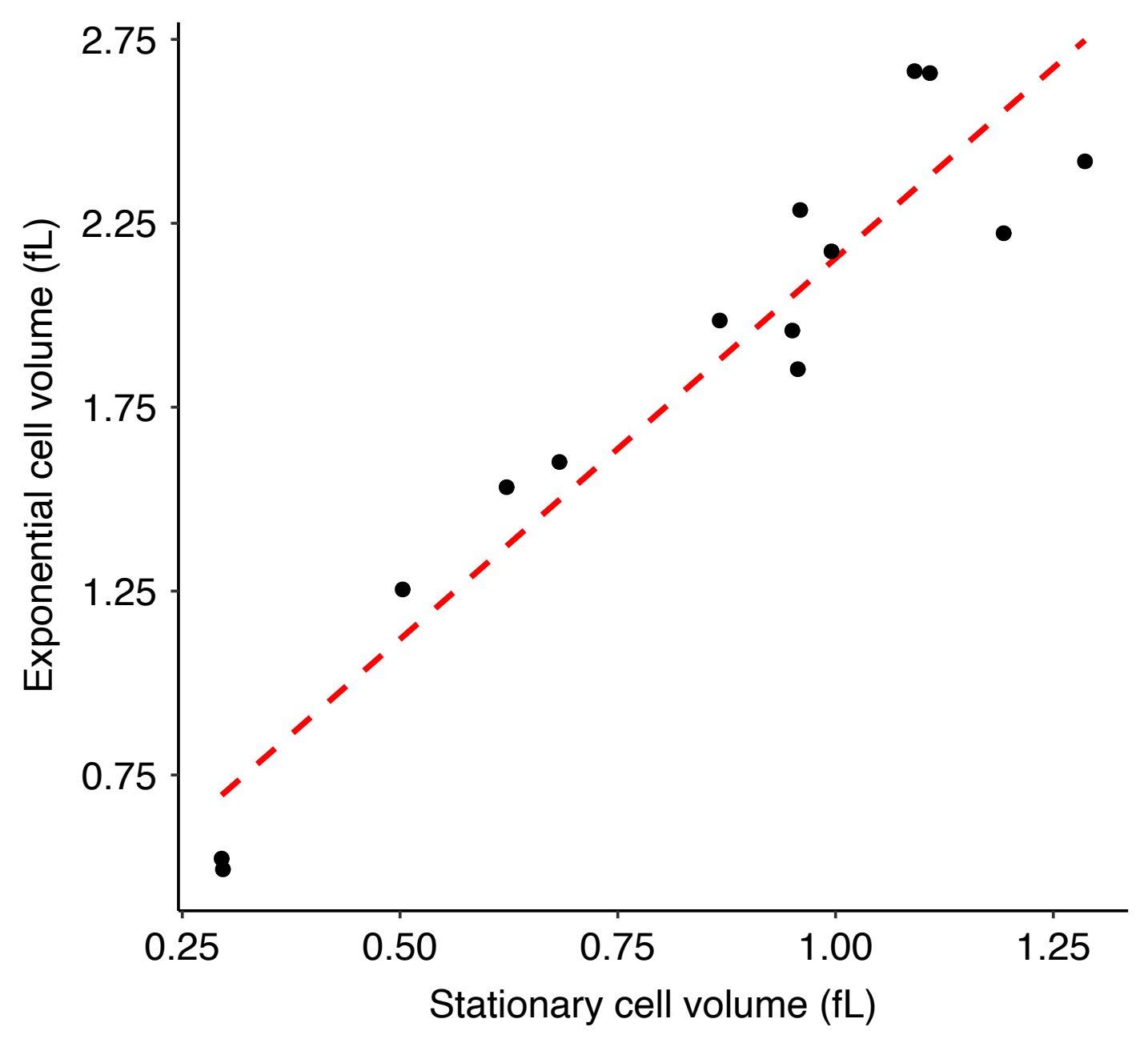

FIG 6. Correlation between cell sizes during exponential growth and in stationary phase.

634 Each point represents the average over 3 replicates of the median cell volume in each

635 growth phase using the data shown in FIG 5. Kendall's coefficient $\tau=0.7582, N=14, p$ $\ll 0.0001$. 
bioRxiv preprint doi: https://doi.org/10.1101/2020.08.13.250415; this version posted August 14, 2020. The copyright holder for this preprint (which was not certified by peer review) is the author/funder, who has granted bioRxiv a license to display the preprint in perpetuity. It is made available under aCC-BY-NC-ND 4.0 International license.

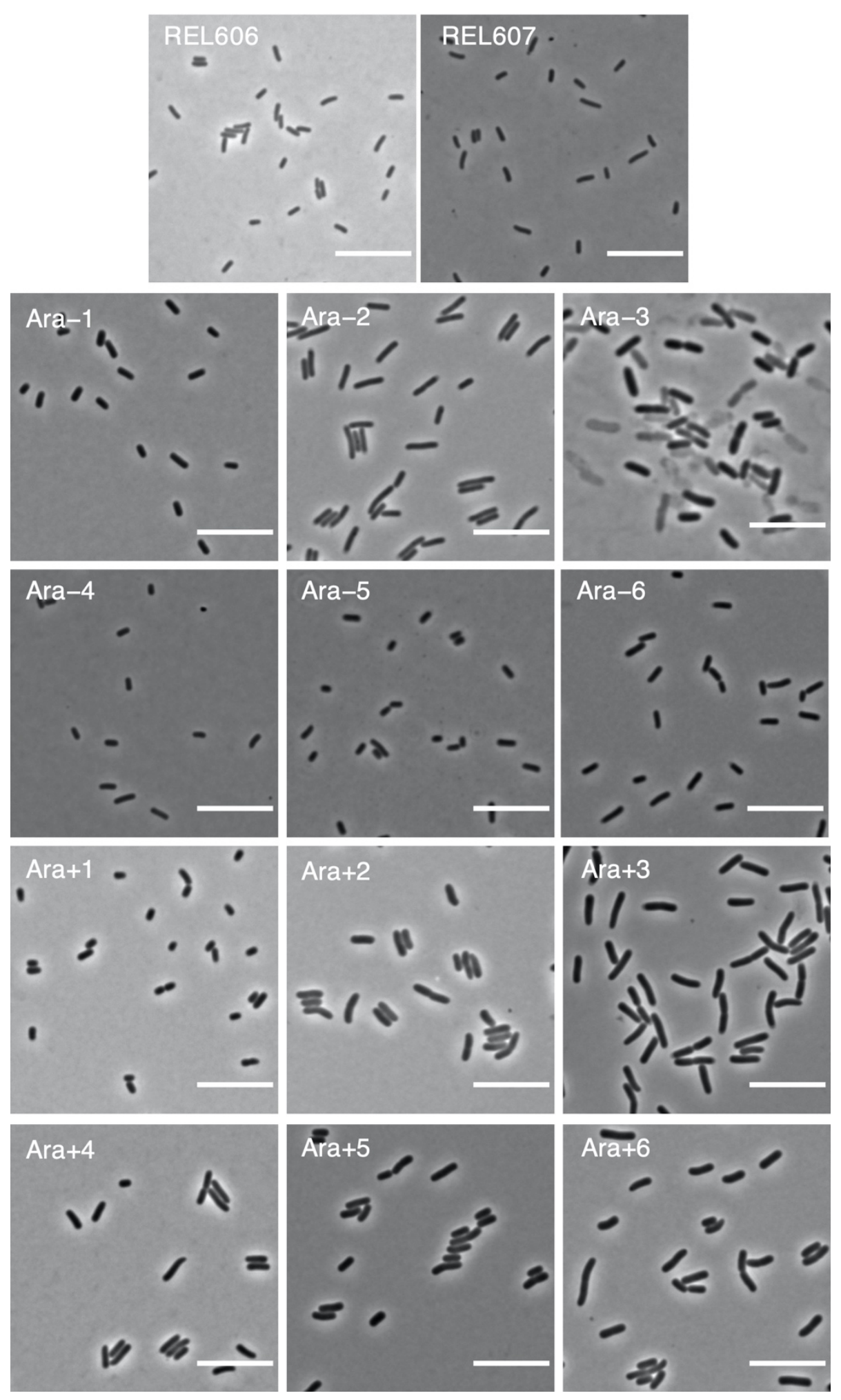


639 FIG 7. Representative micrographs of ancestors (REL606 and REL607) and evolved

640 clones from each population at 50,000 generations. Phase-contrast images were taken

641 at $100 \times$ magnification. Scale bars are $10 \mu \mathrm{m}$. 


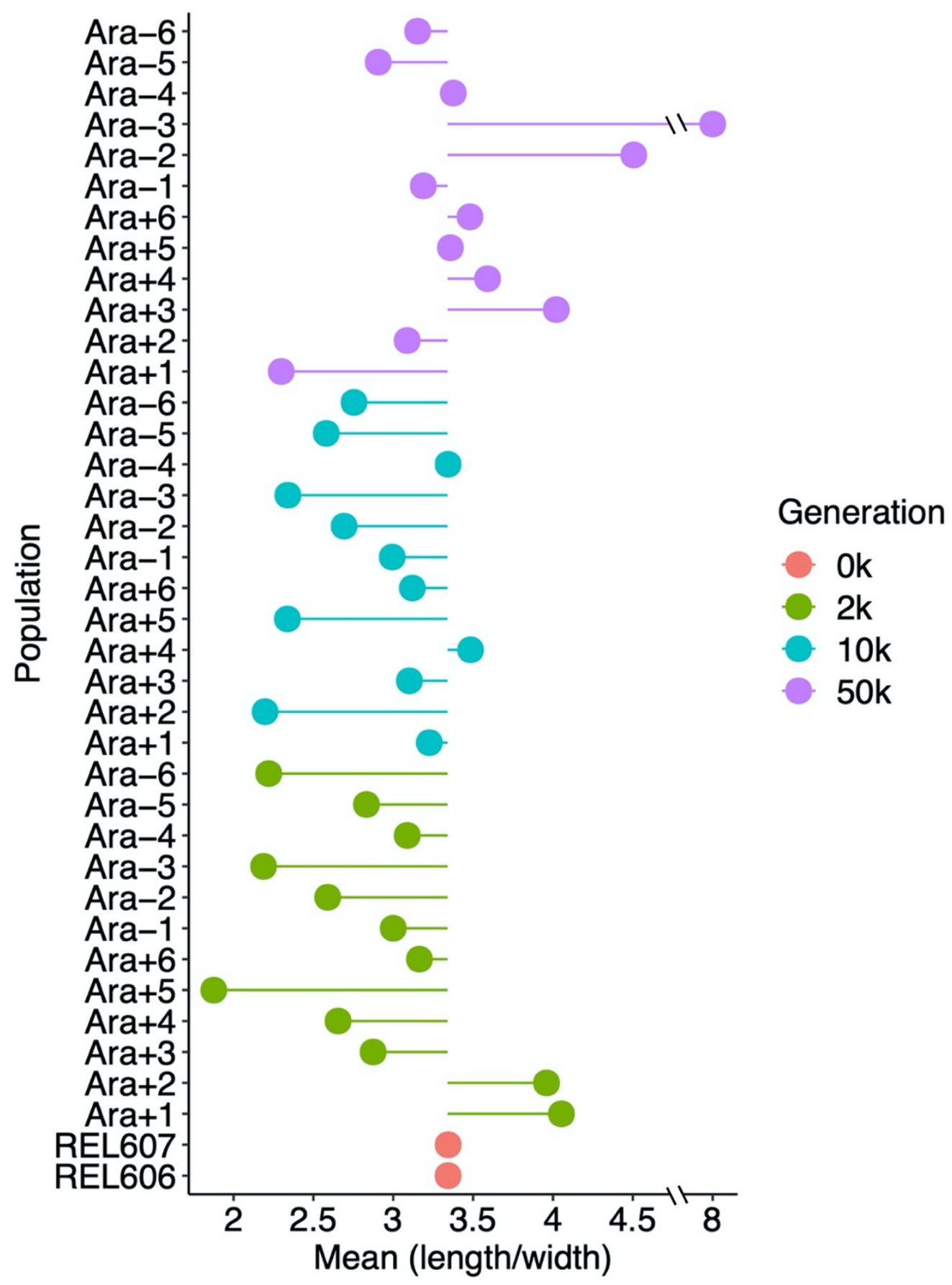

644 FIG 8. Average cell aspect ratios (length/width) of ancestral and evolved clones. Each

645 point shows the mean ratio for the indicated sample. The lines show deviations in the 
bioRxiv preprint doi: https://doi.org/10.1101/2020.08.13.250415; this version posted August 14,2020. The copyright holder for this preprint (which was not certified by peer review) is the author/funder, who has granted bioRxiv a license to display the preprint in perpetuity. It is made available under aCC-BY-NC-ND 4.0 International license.

646 aspect ratio from the ancestral state. The mean aspect ratios were calculated from three

647 replicate assays in all but 4 cases (Ara-4 at 10,000 generations; Ara-2, Ara-4, and Ara-5

648 at 50,000 generations), which had two replicates each. 
A

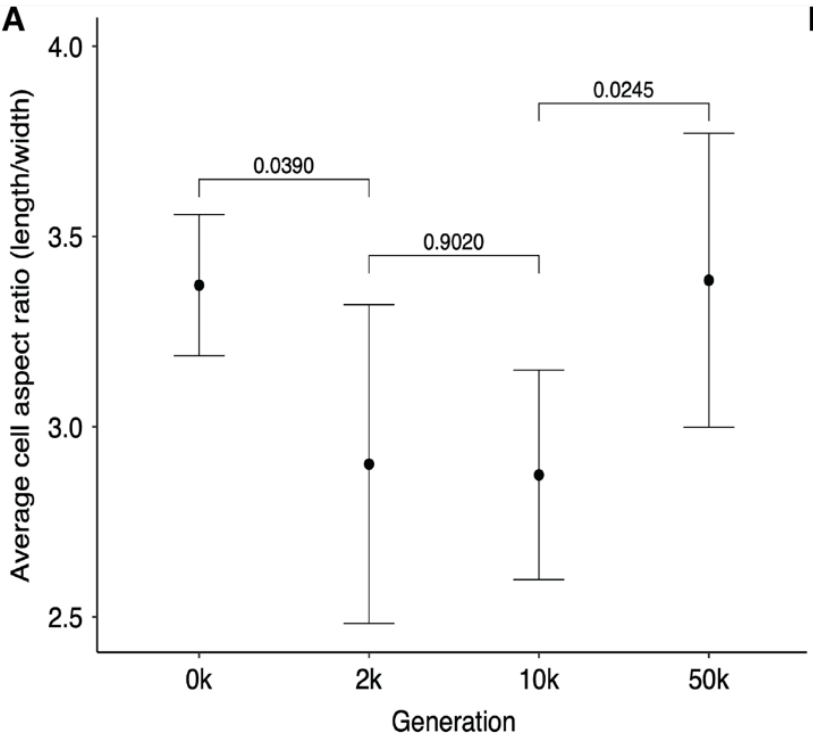

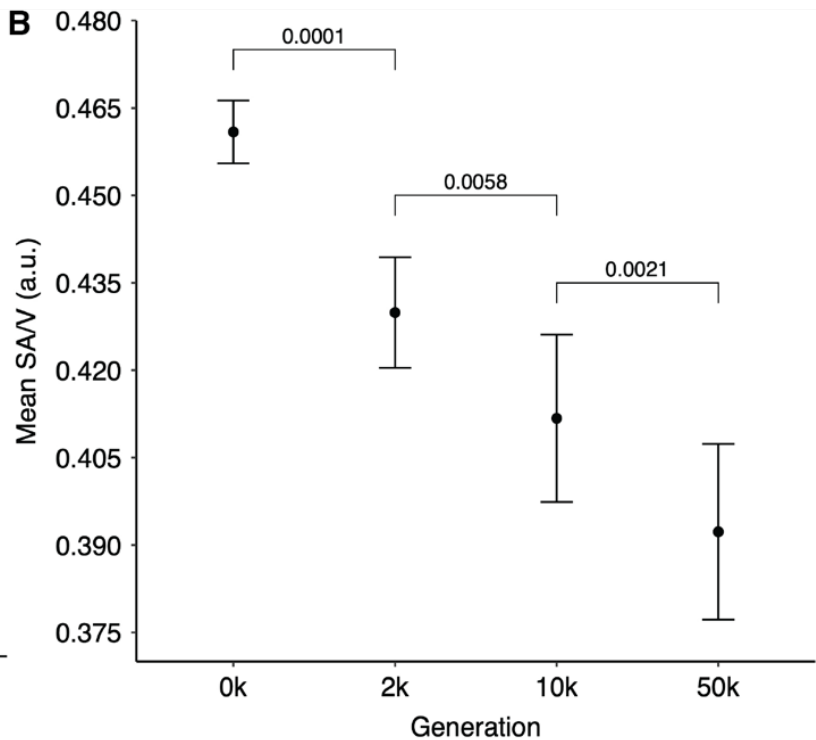

650

651 FIG. 9. Tests of changes over time in cell aspect and surface-to-volume (SA/V) ratios.

652 (A) Evolutionary reversal of cell aspect ratio. Each point is the grand mean of the cell

653 aspect ratio (length/width) for the ancestors and evolved clones. $\mathrm{N}=12$, except at 50,000

654 generations, where $\mathrm{N}=11$ after excluding the outlier clone from the Ara-3 population.

655 Errors bars are 95\% confidence intervals, and brackets show the statistical significance

656 ( $p$ value) based on two-tailed $t$-tests. The tests were paired for clones sampled from the

657 same population at the consecutive time points, and the Ara-3 population was excluded

658 from the final test. (B) Monotonic decline in SA/V ratio over 50,000 generations. Each

659 point shows the grand mean of the average ratio calculated for the ancestor and evolved 
bioRxiv preprint doi: https://doi.org/10.1101/2020.08.13.250415; this version posted August 14, 2020. The copyright holder for this preprint (which was not certified by peer review) is the author/funder, who has granted bioRxiv a license to display the preprint in perpetuity. It is made available under aCC-BY-NC-ND 4.0 International license.

660 clones. Error bars are 95\% confidence intervals, and brackets show the statistical

661 significance ( $p$ value) based on one-tailed paired $t$-tests. 


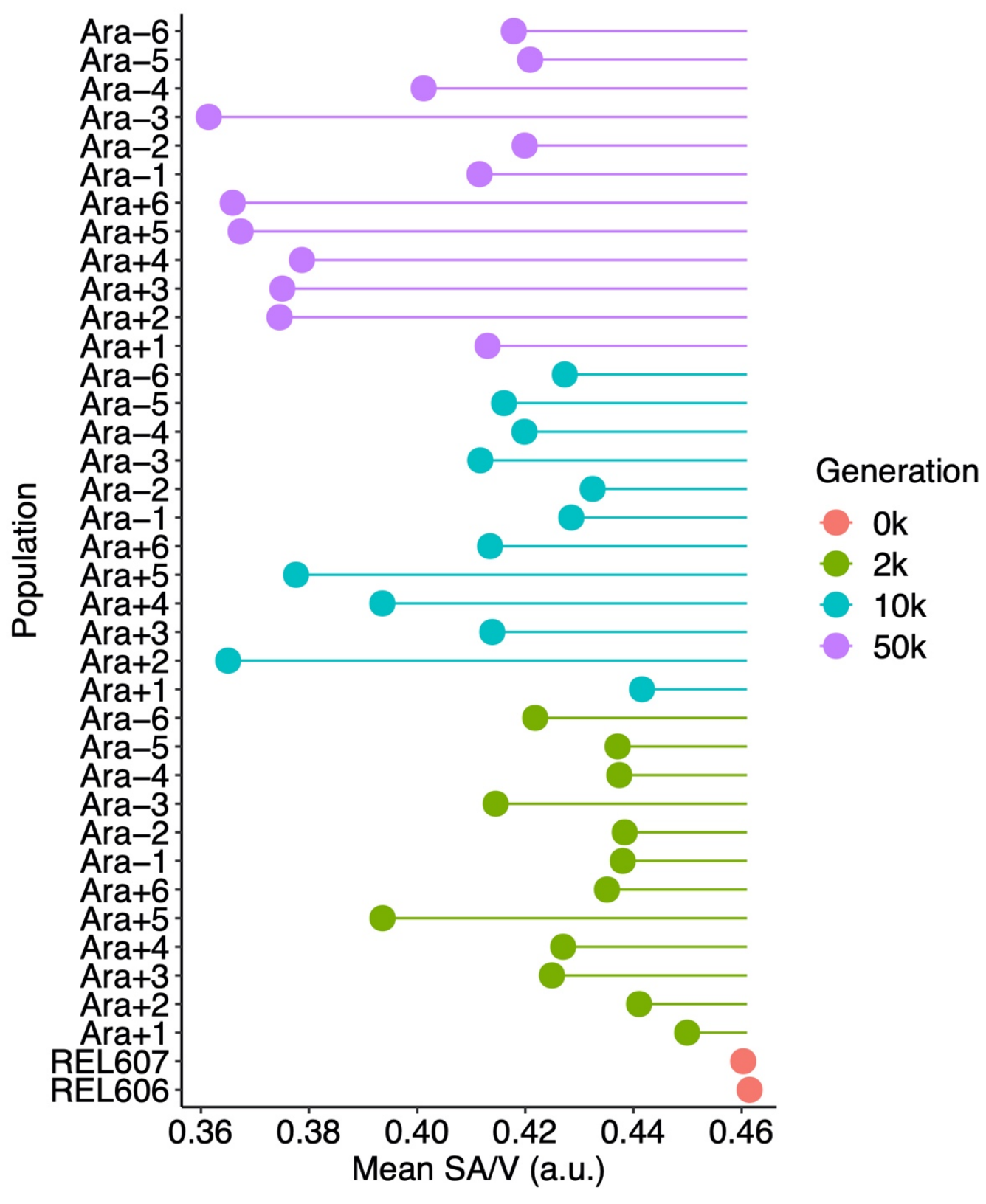

664

665 FIG 10. Average surface area-to-volume ratio (SA/V) of ancestral and evolved clones.

666 The surface area and volume of individual cells were calculated from microscopic images,

667 as described in the text, and their ratio has arbitrary units (a.u.) proportional to $\mu \mathrm{m}^{-1}$. Each 
668 point shows the mean ratio for the indicated sample. The lines show deviations in the

669 ratio from the ancestral state. The means were calculated from three replicate assays in

670 all but 4 cases (Ara-4 at 10,000 generations; Ara-2, Ara-4, and Ara-5 at 50,000

671 generations), which had two replicates each. 


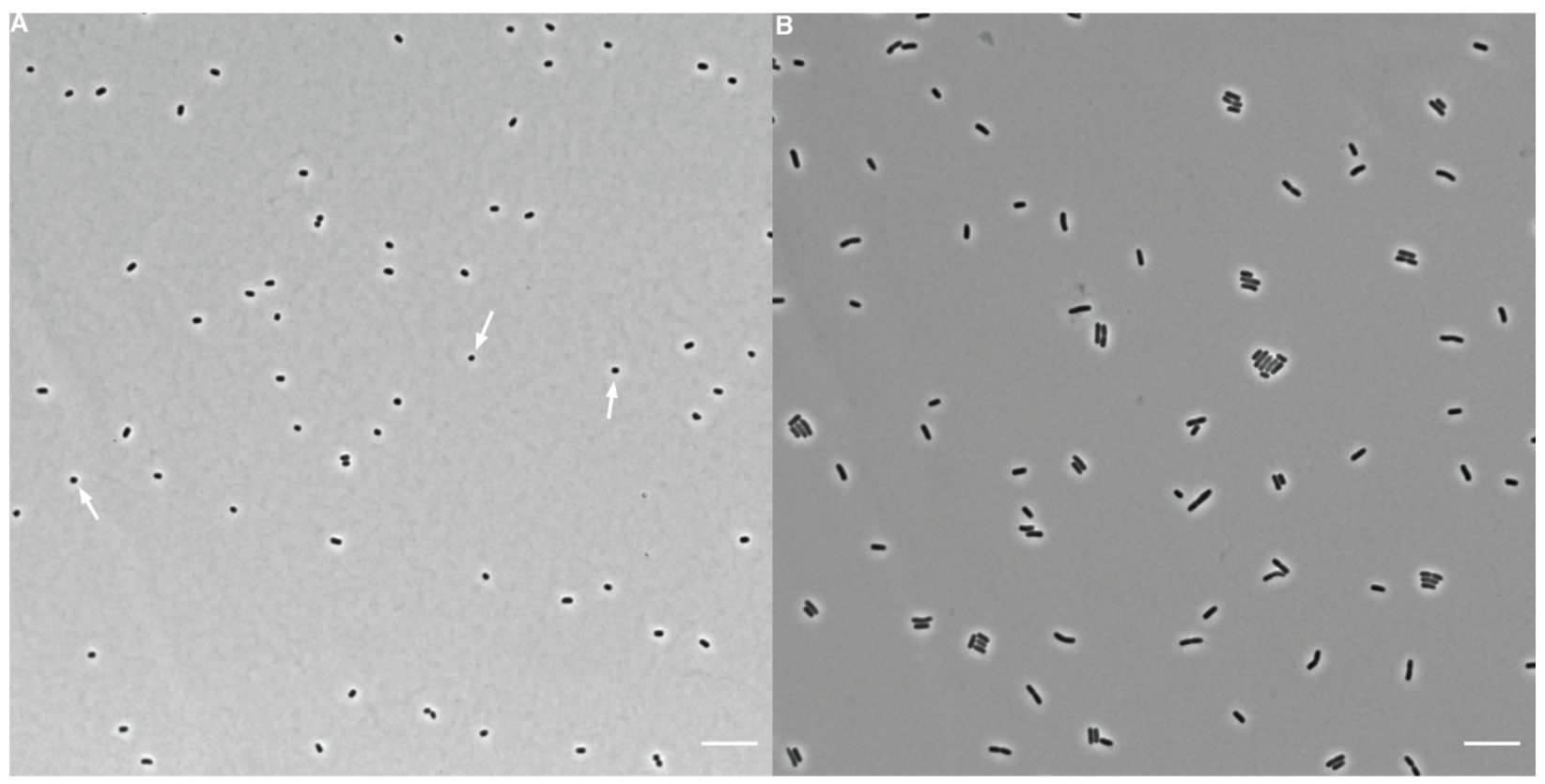

674 FIG 11. Representative micrographs of cells from (A) 2,000-generation and (B) 50,000-

675 generation clones of the Ara+5 population. Phase contrast images were taken on an

676 inverted microscope at $100 \times$ magnification. Scale bars are $10 \mu \mathrm{m}$. Arrows point to

677 examples of nearly spherical cells in the earlier sample, which are not seen in the later

678 one. 

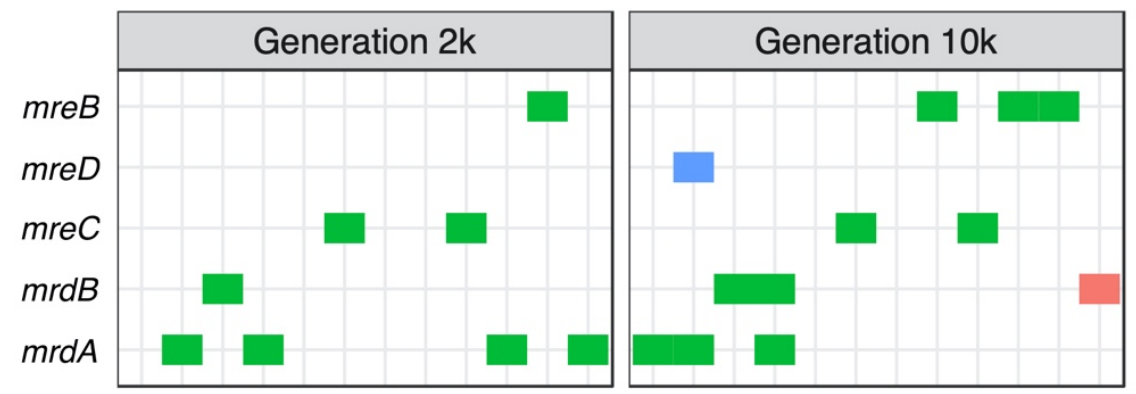

T

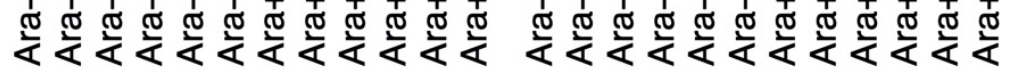

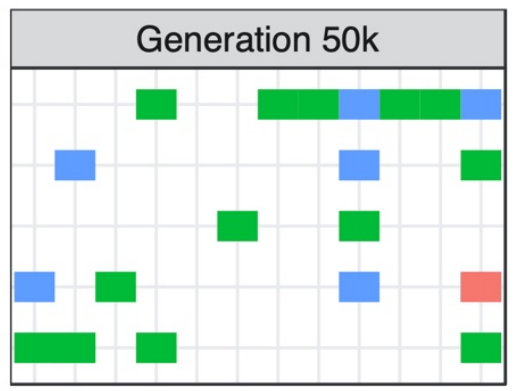

T

Mutation Indel Nonsynonymous Synonymous

FIG 12. Parallel mutations in genes known to be involved in the maintenance of rod50,000 generations. Populations Ara-2, Ara-4, Ara +3 , and Ara +6 evolved hypermutable phenotypes between generations 2,000 and 10,000; populations Ara-1 and Ara-3 did so in lineages with a history of elevated point-mutation rates. 


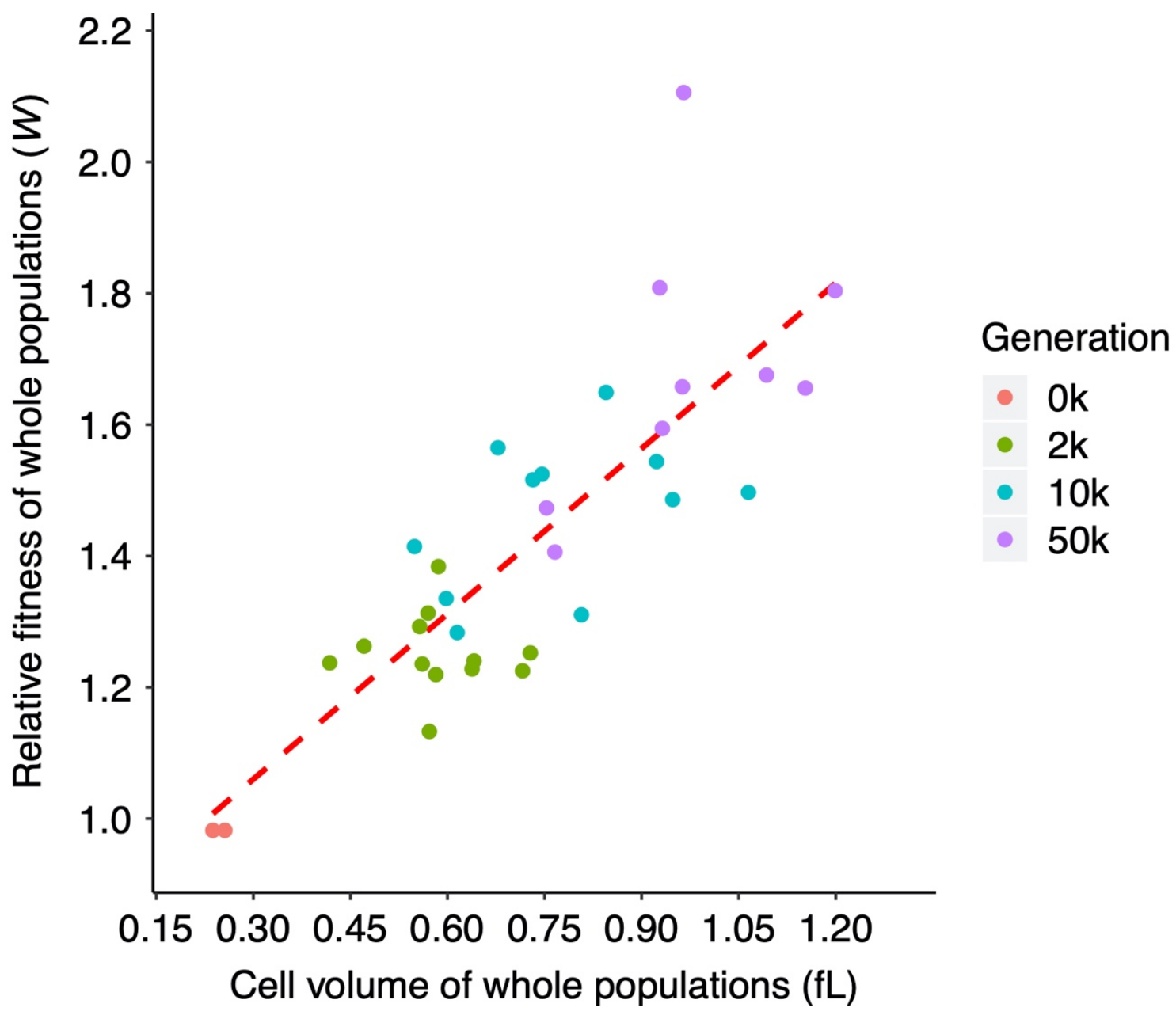

689 FIG 13. Correlation between mean fitness relative to the LTEE ancestor and grand

690 median cell volumes, both based on whole-population samples. Four points (Ara+6 at

691 10,000 generations; Ara-2, Ara-3, and Ara+6 at 50,000 generations) are absent due to

692 missing fitness values reported by Wiser et al. (2013). Kendall's $\tau=0.6066, N=34, p<$

6930.0001. 


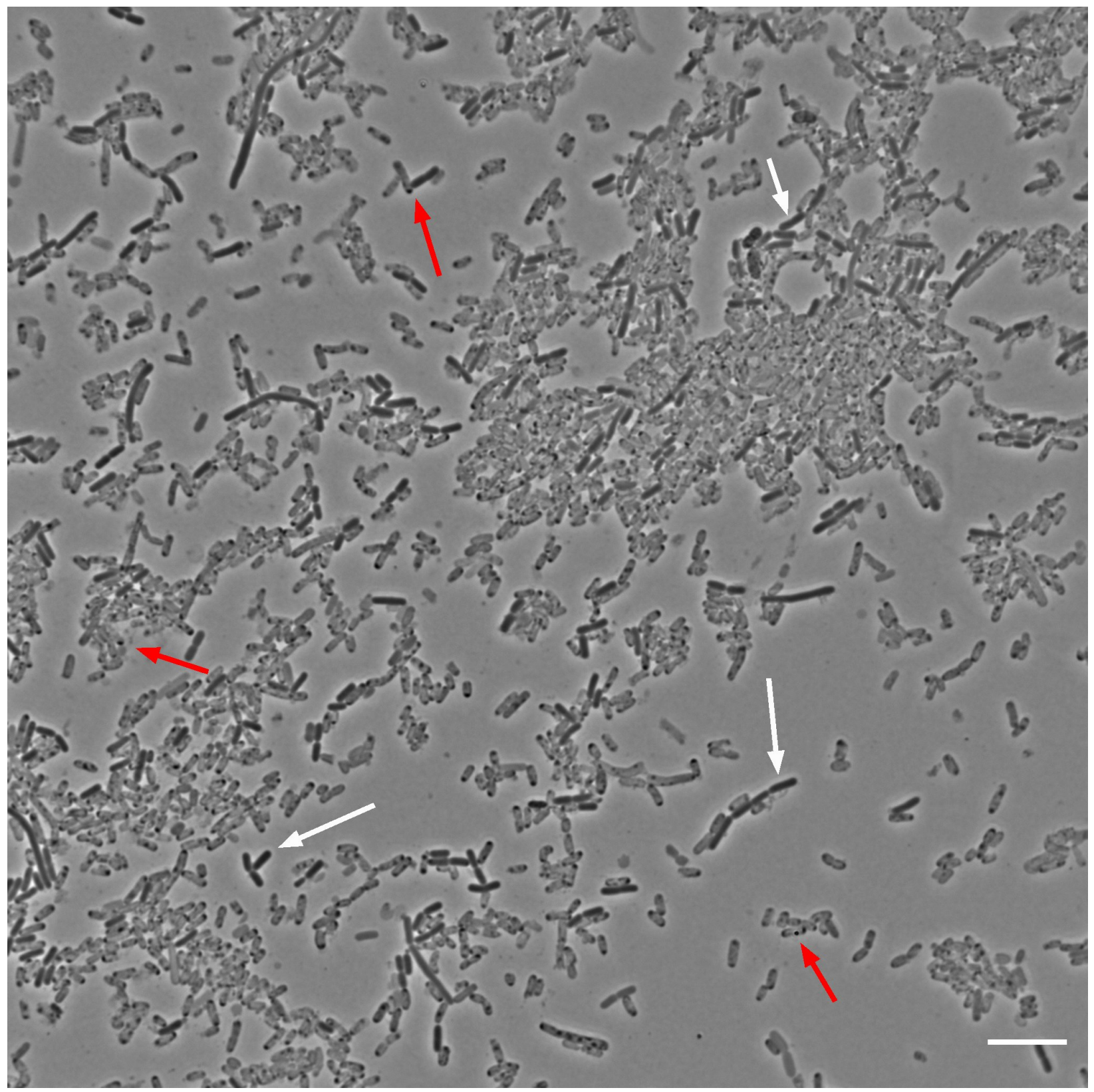

696 FIG 14. Representative micrograph of 50,000-generation $\mathrm{Cit}^{+}$clone from population

697 Ara-3 grown in DM0. As shown in FIG 7, we observed translucent "ghost" cells in the

698 only population that evolved the capacity to use citrate in the LTEE medium (DM25). This

699 clone can also grow on citrate alone in the same medium except without glucose (DM0), 
700 which increased the proportion of presumably dead or dying ghost cells. Red arrows point

701 to several ghost cells, some of which have darker punctate inclusions; white arrows point

702 to several more typically opaque and presumably viable cells. Scale bar is $10 \mu \mathrm{m}$. 

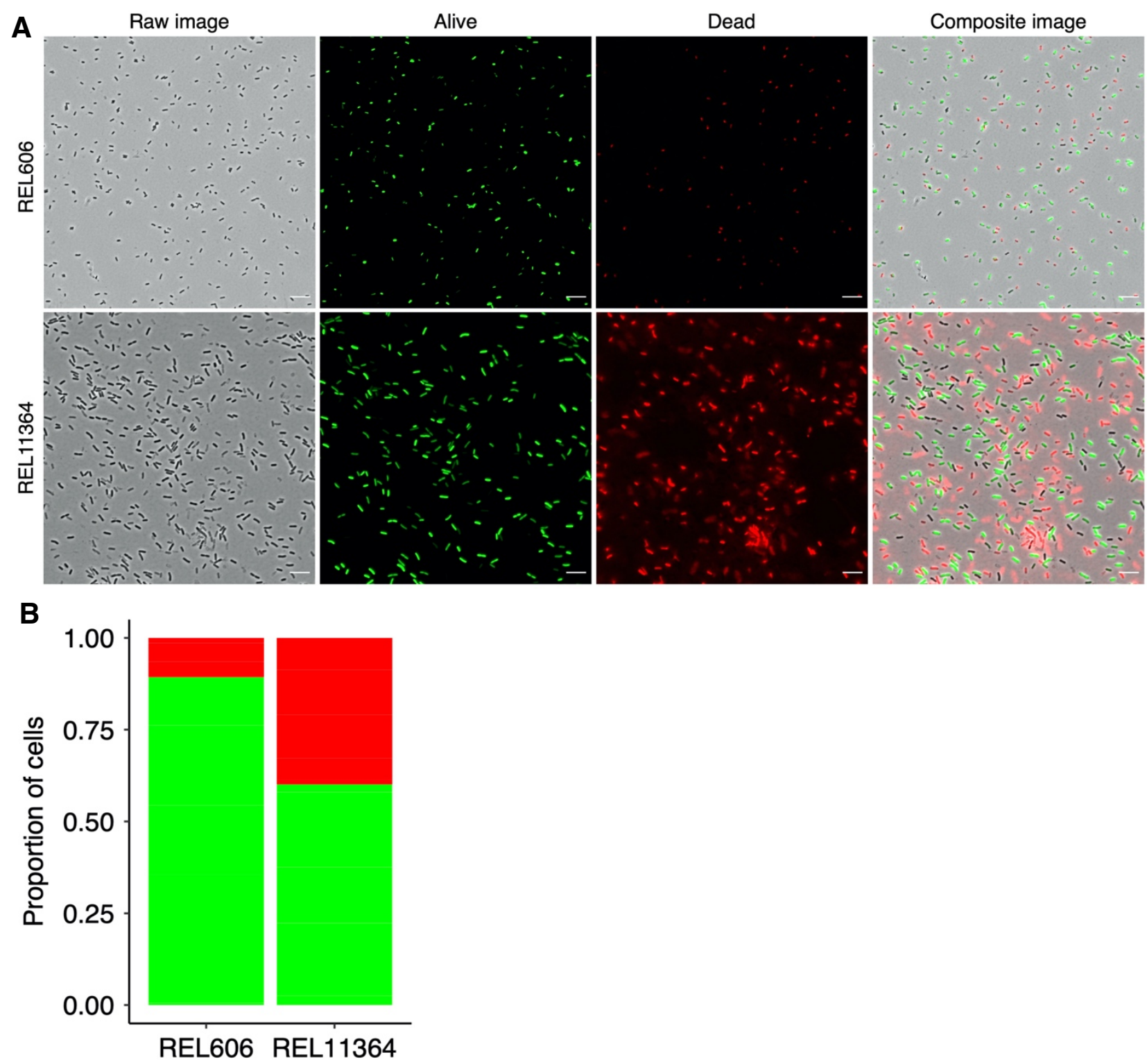

Clone

705 FIG 15. Comparison of cell death in the ancestor and $\mathrm{Cit}^{+}$clone. (A) Representative

706 micrographs showing live-dead staining of the LTEE ancestor (REL606) and the 50,000-

707 generation $\mathrm{Cit}^{+}$clone from population Ara-3 (REL11364), both grown in DM25. Scale

708 bars are $10 \mu \mathrm{m}$. (B) Proportions of cells scored as alive (green) or dead (red), based on 
bioRxiv preprint doi: https://doi.org/10.1101/2020.08.13.250415; this version posted August 14, 2020. The copyright holder for this preprint (which was not certified by peer review) is the author/funder, who has granted bioRxiv a license to display the preprint in perpetuity. It is made available under aCC-BY-NC-ND 4.0 International license.

709 two-color stain assay. For each clone, we assayed cells from 5 biological replicates, which

710 have been pooled in this figure. 


\section{Materials and Methods}

713 Strains. The E. coli LTEE is described in detail elsewhere $(39,42,44)$. In short, 12

714 populations were derived from a common ancestral strain, REL606. Six populations

715 descend directly from REL606. The other six descend from REL607, which differs from

716 REL606 by two selectively neutral mutations (55). Whole-population samples and

717 clones from each population have been frozen at 500-generation intervals. These

718 materials permit the retrospective analysis of genotypic and phenotypic evolution. In this

719 study, we used both clones (Table S1) and whole-population samples (Table S2) from

$7202,000,10,000$ and 50,000 generations.

722 Culture conditions. Samples from the freezer were slightly thawed, inoculated into LB

723 broth, and grown overnight at $37^{\circ} \mathrm{C}$. These cultures were diluted 1:10,000 in $9.9 \mathrm{~mL}$

724 Davis Mingioli medium containing $25 \mathrm{ug} \mathrm{mL}^{-1}$ glucose (DM25). Cultures were incubated

725 at $37^{\circ} \mathrm{C}$ in $50-\mathrm{mL}$ Erlenmeyer flasks, with orbital shaking at $120 \mathrm{rpm}$ for $24 \mathrm{~h}$. These

726 conditions are the same as those used in LTEE. The following day, we diluted cultures 
$727 \quad 1: 100$ in fresh DM25 and grew them for $2 \mathrm{~h}$ or $24 \mathrm{~h}$ for exponential and stationary phase

728 cell measurements, respectively.

730 Volumetric and shape measurements. Cell sizes were measured using two analytical

731 approaches. In one, we used the Coulter Multisizer 4e (Beckman), an electronic device

732 that measures cell volume following the Coulter principle (80). In this study, we used a

$733 \quad 30-\mu \mathrm{m}$ aperture, and we measured particle sizes in the range from $2 \%$ to $60 \%$ of the

734 aperture diameter, which corresponds to a volumetric range of $0.113 \mathrm{fL}$ to $3,054 \mathrm{fL}$.

735 However, we excluded any particles over $6 \mathrm{fL}$ in our analyses. On several occasions we

736 calibrated the aperture using 5.037- $\mu \mathrm{m}$ diameter wide latex beads (Beckman). The

737 measured variance in bead size was below the recommended threshold of $2.0 \%$ at

738 each calibration.

739 In the second approach, we imaged cells using phase-contrast microscopy, and

740 we processed the resulting micrographs using the SuperSegger package (52).

741 SuperSegger automatically identifies the boundary between cells and segments the

742 individual cells on a micrograph. It returns measurements aligned to the midline of each

743 cell for the long and short axes, which we used as length and width, respectively. The 
744 volume (in arbitrary units) of a cell is approximated by integrating over all segments

745 within the cell's boundaries (82). Given the low density of cells in DM25 even at

746 stationary phase, and to obtain sufficient numbers of cells for analysis in many visual

747 fields, we concentrated most cultures 2-fold by centrifugation at 7,745 $\mathrm{g}$ for $2 \mathrm{~min}$.

748 Clones from two populations at generation 50,000 (Ara-1 and Ara-4) required 4-fold

749 concentration. Samples from another population at generation 50,000 (Ara-3) were

750 imaged without concentrating the medium. We then spotted 3- $\mu$ l samples from each

751 processed culture onto 1\% agarose pads, and we imaged the cells using a Nikon

752 Eclipse Ti-U inverted microscope.

754 Analysis of cell mortality in population Ara-3. We reanalyzed data on cell viability

755 collected for two clones: the LTEE ancestor (REL606), and the 50,000-generation clone

756 from population Ara-3 (REL11364) that evolved the novel ability to use citrate as a

757 source of carbon and energy $\left(\mathrm{Cit}^{+}\right)$. We used the BacLight viability kit for microscopy

758 (ThermoFisher \#L7007) following the manufacturer's directions for fluorescently labeling

759 cells. In short, we mixed the provided components A and B in equal amounts, added 1

$760 \mu$ to $10-\mathrm{mL}$ stationary-phase DM25 cultures of each clone, and incubated them for 20 
$761 \mathrm{~min}$ in the dark to prevent photobleaching. The two components contain two fluorescent

762 dyes that differentially stain presumptively live and dead cells. For the Cit+ clone only,

763 we also examined cells in DM0 medium, which contains the same concentration of

764 citate as DM25, but no glucose. Full methods and additional results in the context of

765 other work are reported in Blount et al. (49).

767 Genomic and fitness data. We integrated our analyses of cell size and shape with

768 previously published datasets on the fitness of the evolved bacteria relative to their

769 ancestor, and on the mutations present in the various clones obtained by sequencing

770 and comparing the evolved and ancestral genomes. The fitness data were previously

771 collected by Wiser et al. (42), who performed competition assays between evolved

772 populations and reciprocally marked ancestors. We downloaded these data from the

773 Dryad Digital Repository (accession https://doi.org/10.5061/dryad.0hc2m). The

774 complete genomes of the ancestral strain and evolved clones used in our study were

775 sequenced by Jeong et al. (81) and Tenaillon et al. (55), respectively. We used an

776 online tool (http://barricklab.org/shiny/LTEE-Ecoli/) to identify all of the mutations that 
777 occurred in several genes ( $m r e B, m r e C, m r e D, m r d A$, and $m r d B$ ) known to be involved

778 in maintaining rod-shaped cells in E. coli.

780 Statistical analyses. Statistical analyses were performed in R (Version 3.5.0, 2018-04-

781 23). Our datasets and $R$ analysis scripts will be made available on the Dryad Digital

782 Repository (DOI pending publication).

\section{Acknowledgments}

787 We thank Terence Marsh, Charles Ofria, Gemma Reguera, and Chris Waters for

788 feedback as this research progressed, and members of the Lenski lab for valuable

789 discussions. We also thank Rohan Maddemsetti and Zachary Blount for their comments

790 on the manuscript. This work was supported in part by a grant from the National

791 Science Foundation (currently DEB-1951307), the BEACON Center for the Study of

792 Evolution in Action (DBI-0939454), and the USDA National Institute of Food and

793 Agriculture (MICL02253). Any opinions, findings, and conclusions or recommendations

794 expressed in this material are those of the authors and do not necessarily reflect the 795 views of the funders. 


\section{References}

798 1. Marshall WF, Young KD, Swaffer M, Wood E, Nurse P, Kimura A, Frankel J,

799 Wallingford J, Walbot V, Qu X, Roeder AHK. 2012. What determines cell size?

$800 \quad$ BMC Biol 10:101.

801 2. Young KD. 2006. The selective value of bacterial shape. Microbiol Mol Biol Rev $70: 660-670$.

803 3. Corno G, Jürgens K. 2006. Direct and indirect effects of protist predation on population size structure of a bacterial strain with high phenotypic plasticity. Appl Environ Microbiol 72:78-86.

4. Batani G, Pérez G, Martínez de la Escalera G, Piccini C, Fazi S. 2016. community composition and size distribution. J Freshw Ecol 31:609-623.

5. Champion JA, Walker A, Mitragotri S. 2008. Role of particle size in phagocytosis

6. Doshi N, Mitragotri S. 2010. Macrophages recognize size and shape of their targets. PLoS One 5:e10051.

813 7. St-Pierre F, Endy D. 2008. Determination of cell fate selection during phage lambda infection. Proc Natl Acad Sci U S A 105:20705-20710.

815 8. Choi C, Kuatsjah E, Wu E, Yuan S. 2010. The effect of cell size on the burst size of T4 bacteriophage infections of Escherichia coli B23. JEMI 14:85-91.

817 9. Koch AL. 2003. Bacterial wall as target for attack: past, present, and future research. Clin Microbiol Rev 16:673-687. 
819 10. Miller C. 2004. SOS response induction by beta-lactams and bacterial defense against antibiotic lethality. Science 305:1629-1631.

821 11. Nikolaidis I, Favini-Stabile S, Dessen A. 2014. Resistance to antibiotics targeted to the bacterial cell wall. Protein Sci 23:243-259.

823 12. Cooper GM. 2000. The Cell: A Molecular Approach, 2nd edition. Sinauer, $824 \quad$ Sunderland, Mass.

825 13. Chien AC, Hill NS, Levin PA. 2012. Cell size control in bacteria. Curr Biol 22:R340-R349.

827 14. Schaechter M, Maaloe O, Kjeldgaard NO. 1958. Dependency on medium and temperature of cell size and chemical composition during balanced growth of Salmonella typhimurium. J Gen Microbiol 19:592-606.

15. Bremer H, Dennis PP. 2008. Modulation of chemical composition and other parameters of the cell by growth rate. Escherichia coli and Salmonella typhimurium: Cellular and Molecular Biology 3:1-2.

833 16. Akerlund T, Nordstrom K, Bernander R. 1995. Analysis of cell size and DNA content in exponentially growing and stationary-phase batch cultures of Escherichia coli. J Bacteriol 177:6791-6797.

836 17. Wang JD, Levin PA. 2009. Metabolism, cell growth and the bacterial cell cycle. $837 \quad$ Nat Rev Microbiol 7:822-827.

838 18. Valgepea K, Adamberg K, Seiman A, Vilu R. 2013. Escherichia coli achieves faster growth by increasing catalytic and translation rates of proteins. Mol Biosyst $9: 2344-2358$. 
841 19. Amir A. 2017. Is cell size a spandrel? ELife 6:1-8.

842 20. Gould SJ, Lewontin RC. 1979. The spandrels of San Marco and the panglossian paradigm: a critique of the adaptationist programme.Proc R Soc Lond B Biol Sci

845 21. Heim NA, Payne JL, Finnegan S, Knope ML, Kowalewski M, Lyons SK, McShea and the size limits of life. Proc R Soc Lond B Biol Sci 284:20171039.

22. Rappé MS, Connon SA, Vergin KL, Giovannoni SJ. 2002. Cultivation of the ubiquitous SAR11 marine bacterioplankton clade. Nature 418:630-633.

23. Giovannoni SJ. 2017. SAR11 bacteria: the most abundant plankton in the oceans. Ann Rev Mar Sci 9:231-255.

852 24. Angert ER, Clements KD, Pace NR. 1993. The largest bacterium. Nature 362:239-241.

854 25. Levin PA, Angert ER. 2015. Small but mighty: cell size and bacteria. Cold Spring Harb Perspect Biol 7:a019216.

$85626 . \quad$ Mika JT, van den Bogaart G, Veenhoff L, Krasnikov V, Poolman B. 2010. Molecular sieving properties of the cytoplasm of Escherichia coli and

859 27. Mika JT, Poolman B. 2011. Macromolecule diffusion and confinement in prokaryotic cells. Curr Opin Biotechnol 22:117-126 .

861 28. Schavemaker PE, Boersma AJ, Poolman B. 2018. How important is protein 862 diffusion in prokaryotes? Front Mol Biosci 5:1-16. 
863 29. Yang DC, Blair KM, Salama NR. 2016. Staying in shape: the impact of cell shape on bacterial survival in diverse environments. Microbiol Mol Biol Rev 80:187-203.

865 30. Sourjik V, Wingreen NS. 2012. Responding to chemical gradients: bacterial chemotaxis. Curr Opin Cell Biol 24:262-268.

867 31. Tucker JD, Siebert CA, Escalante M, Adams PG, Olsen JD, Otto C, Stokes DL, Hunter CN. 2010. Membrane invagination in Rhodobacter sphaeroides is initiated at curved regions of the cytoplasmic membrane, then forms both budded and

32. Ojkic N, Serbanescu D, Banerjee S. 2019. Surface-to-volume scaling and aspect ratio preservation in rod-shaped bacteria. ELife 8:1-11.

873 33. Harris LK, Theriot JA. 2018. Surface area to volume ratio: a natural variable for bacterial morphogenesis. Trends Microbiol 26:815-832.

875 34. Kawecki TJ, Lenski RE, Ebert D, Hollis B, Olivieri I, Whitlock MC. 2012. Experimental evolution. Trends Ecol Evol 27:547-560.

877 35. Ratcliff WC, Denison RF, Borrello M, Travisano M. 2012. Experimental evolution 878 of multicellularity. Proc Natl Acad Sci U S A 109:1595-1600.

879 36. Graves JL, Hertweck KL, Phillips MA, Han MV, Cabral LG, Barter TT, Greer LF, 880 Burke MK, Mueller LD, Rose MR. 2017. Genomics of parallel experimental 881 evolution in Drosophila. Mol Biol Evol 34:831-842.

882 37. Lenski RE, Ofria C, Pennock RT, Adami C. 2003. The evolutionary origin of 883 complex features. Nature 423:139-144. 
884 38. LaBar T, Adami C. 2017. Evolution of drift robustness in small populations. Nat Commun 8:1012.

886 39. Lenski RE, Rose MR, Simpson SC, Tadler SC. 1991. Long-term experimental evolution in Escherichia coli. I. Adaptation and divergence during 2,000 generations. Am Nat 138:1315-1341.

889 40. Lenski RE, Travisano M. 1994. Dynamics of adaptation and diversification: a 10,000-generation experiment with bacterial populations. Proc Natl Acad Sci U S A 91:6808-6814.

892 41. Vasi F, Travisano M, Lenski RE. 1994. Long-term experimental evolution in Escherichia coli. II. Changes in life-history traits during adaptation to a seasonal environment. Am Nat 144:432-456.

42. Wiser MJ, Ribeck N, Lenski RE. 2013. Long-term dynamics of adaptation in asexual populations. Science 342:1364-1367.

897 43. Lenski RE, Wiser MJ, Ribeck N, Blount ZD, Nahum JR, Morris JJ, Zaman L, Turner C, Wade B, Maddamsetti R, Burmeister AR, Baird EJ, Bundy J, Grant NA, Card KJ, Rowles M, Weatherspoon K, Papoulis SE, Sullivan R, Clark C, Mulka JS, Hajela N. 2015. Sustained fitness gains and variability in fitness trajectories in the long-term evolution experiment with Escherichia coli. Proc R Soc Lond B Biol Sci 282:20152292.

903 44. Lenski RE. 2017. Experimental evolution and the dynamics of adaptation and genome evolution in microbial populations. ISME J 11:2181-2194. 
905 45. Lenski RE, Mongold JA. 2000. Cell size, shape, and fitness in evolving populations of bacteria. In: Brown J, West G (eds), Scaling in Biology. Oxford University Press, Oxford, pp 221-234.

46. Philippe N, Pelosi L, Lenski RE, Schneider D. 2009. Evolution of penicillinbinding protein 2 concentration and cell shape during a long-term experiment with Escherichia coli. J Bacteriol 191:909-921.

47. Blount ZD, Borland CZ, Lenski RE. 2008. Historical contingency and the evolution of a key innovation in an experimental population of Escherichia coli. Proc Natl Acad Sci U S A 105:7899-7906.

914 48. Blount ZD, Barrick JE, Davidson CJ, Lenski RE. 2012. Genomic analysis of a key innovation in an experimental Escherichia coli population. Nature 489:513-518.

49. Blount ZD, Maddamsetti R, Grant NA, Ahmed ST, Jagdish T, Baxter JA, Sommerfeld BA, Tillman A, Moore J, Slonczewski JL, Barrick JE, Lenski RE. 2020. Genomic and phenotypic evolution of Escherichia coli in a novel citrate-

920 50. Mongold JA, Lenski RE. 1996. Experimental rejection of a nonadaptive explanation for increased cell size in Escherichia coli. J Bacteriol 178:53335334.

923 51. Chang F, Huang KC. 2014. How and why cells grow as rods. BMC Biol 12:54

924 52. Stylianidou S, Brennan C, Nissen SB, Kuwada NJ, Wiggins PA. 2016.

925 SuperSegger : robust image segmentation, analysis and lineage tracking of 926 bacterial cells. Mol Microbiol 102:690-700. 
927 53. Si F, Li D, Cox SE, Sauls JT, Azizi O, Sou C, Schwartz AB, Ericstad MJ, Jun Y,

928 Li X, Jun S. 2017. Invariance of initiation mass and predictability of cell size in

$929 \quad$ Escherichia coli. Curr Biol 27:1278-1287.

930 54. Kruse T, Bork-Jensen J, Gerdes K. 2005. The morphogenetic MreBCD proteins 931 of Escherichia coli form an essential membrane-bound complex. Mol Microbiol 55:78-89.

933 55. Tenaillon O, Barrick JE, Ribeck N, Deatherage DE, Blanchard JL, Dasgupta A, 934 Wu GC, Wielgoss S, Cruveiller S, Médigue C, Schneider D, Lenski RE. 2016.

935 Tempo and mode of genome evolution in a 50,000-generation experiment.

$936 \quad$ Nature 536:165-170.

937 56. Pötter M, Steinbüchel A. 2006. Biogenesis and structure of polyhydroxyalkanoate granules. In: Shively JM (ed), Inclusions in Prokaryotes. Springer, Berlin, pp 110_

57. Jendrossek D. 2009. Polyhydroxyalkanoate granules are complex subcellular organelles (carbonosomes). J Bacteriol 191:3195-3202.

942 58. Al Rowaihi IS, Paillier A, Rasul S, Karan R, Grötzinger SW, Takanabe K, electromicrobial setup: Investigation under stress-inducing conditions. PLoS One

946 59. Obruca S, Sedlacek P, Slaninova E, Fritz I, Daffert C, Meixner K, Sedrlova Z, 947 Koller M. 2020. Novel unexpected functions of PHA granules. Appl Microbiol $948 \quad$ Biotechnol 104:4795-4810. 
949 60. Rozen DE, Schneider D, Lenski RE. 2005. Long-term experimental evolution in

$950 \quad$ Escherichia coli. XIII. Phylogenetic history of a balanced polymorphism. J Mol

$951 \quad$ Evol 61:171-180.

952 61. Grosskopf T, Consuegra J, Gaffé J, Willison J, Lenski RE, Soyer OS, Schneider

D. 2016. Metabolic modelling in a dynamic evolutionary framework predicts adaptive diversification of bacteria in a long-term evolution experiment. BMC Evol Biol 16:163.

956 62. van Dijk B, Meijer J, Cuypers TD, Hogeweg P. 2019. Trusting the hand that feeds: microbes evolve to anticipate a serial transfer protocol as individuals or collectives. BMC Evol Biol 19:201.

959 63. Raskin DM, de Boer PA. 1999a. Rapid pole-to-pole oscillation of a protein required for directing division to the middle of Escherichia coli. Proc Natl Acad Sci U S A 96:4971-4976.

962 64. Raskin DM, de Boer PA. 1999b. MinDE-dependent pole-to-pole oscillation of division inhibitor MinC in Escherichia coli. J Bacteriol 181:6419-6424.

964 65. Huang KC, Meir Y, Wingreen NS. 2003. Dynamic structures in Escherichia coli: Spontaneous formation of MinE rings and MinD polar zones. Proc Natl Acad Sci U S A 100:12724-12728.

967 66. Lutkenhaus J. 2007. Assembly dynamics of the bacterial MinCDE system and spatial regulation of the Z ring. Annu Rev Biochem 76:539-562. 
969 67. Dajkovic A, Lan G, Sun SX, Wirtz D, Lutkenhaus J. 2008. MinC spatially controls bacterial cytokinesis by antagonizing the scaffolding function of FtsZ. Curr Biol 18:235-244.

972 68. Arumugam S, Petrašek Z, Schwille P. 2014. MinCDE exploits the dynamic nature of FtsZ filaments for its spatial regulation. Proc Natl Acad Sci U S A 111:E1192-

$974 \quad$ E1200.

975 69. Ramm B, Heermann T, Schwille P. 2019. The E. coli MinCDE system in the regulation of protein patterns and gradients. Cell Mol Life Sci 76:4245-4273.

977 70. Fischer-Friedrich E, Meacci G, Lutkenhaus J, Chaté H, Kruse K. 2010. Intra- and intercellular fluctuations in Min-protein dynamics decrease with cell length. Proc Natl Acad Sci U S A 107:6134-6139.

980 71. Minton AP. 2006. How can biochemical reactions within cells differ from those in test tubes? J Cell Sci 119:2863-2869.

982 72. Gallet R, Violle C, Fromin N, Jabbour-Zahab R, Enquist BJ, Lenormand R. 2017. 983 The evolution of bacterial cell size: the internal diffusion-constraint

984 hypothesis. ISME J 11:1559-1568.

985 73. Beveridge TJ. 1988. The bacterial surface: general considerations towards design and function. Can J Microbiol 34:363-372.

987 74. Koch AL. 1996. What size should a bacterium be? A question of scale. Annu Rev Microbiol 50:317-348.

989 75. Schulz H, Jorgensen B. 2001. Big bacteria. Annu Rev Microbiol 55:105-137. 
990 76. Golding I, Cox EC. 2006. Physical nature of bacterial cytoplasm. Phys Rev Lett 96:98-102.

992 77. Beg QK, Vazquez A, Ernst J, de Menezes MA, Bar-Joseph Z, Barabási A-L, Oltvai ZN. 2007. Intracellular crowding defines the mode and sequence of substrate uptake by Escherichia coli and constrains its metabolic activity. Proc Natl Acad Sci U S A 104:12663-12668.

78. Ando T, Skolnick J. 2010. Crowding and hydrodynamic interactions likely dominate in vivo macromolecular motion. Proc Natl Acad Sci U S A 107:1845718462.

79. Dill KA, Ghosh K, Schmit JD. 2011. Physical limits of cells and proteomes. Proc Natl Acad Sci U S A 108: 17876-17882.

1001 80. Don M. 2003. The Coulter principle: foundation of an industry. JALA 8:72-81.

1002 81. Jeong H, Barbe V, Lee CH, Vallenet D, Yu DS, Choi S-H, Couloux A, Lee S-W, Yoon SH, Cattolico L, Hur C-G, Park H-S, Ségurens B, Kim SC, Oh TK, Lenski RE, Studier FW, Daegelen P, Kim JF. 2009. Genome sequences of Escherichia coli B strains REL606 and BL21(DE3). J Mol Biol 394:644-652. subpixel precision analysis of bacterial morphogenesis and intracellular spatiotemporal dynamics. Mol Microbiol 80:612-627. 